\title{
Asymmetric synthesis of Isoxazol-5-ones and Isoxazolidin-5-ones
}

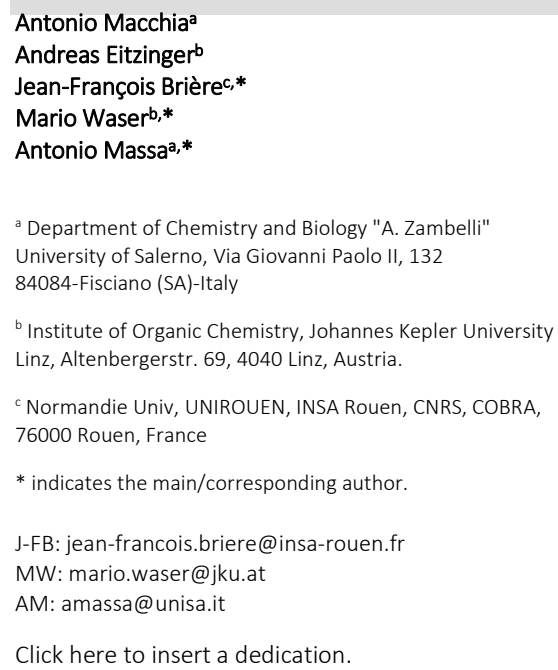

\section{1) Introduction}

Isoxazol-5-ones $\mathbf{2}$ and isoxazolidin-5-ones $\mathbf{3}$ are important classes of functional molecules belonging to a large family of heterocyclic compounds, the isoxazoles 1 (Figure 1). In particular, isoxazol-5ones and isoxazolidin-5-ones have been found in a variety of natural products (Figure 2), isolated for example from lentil

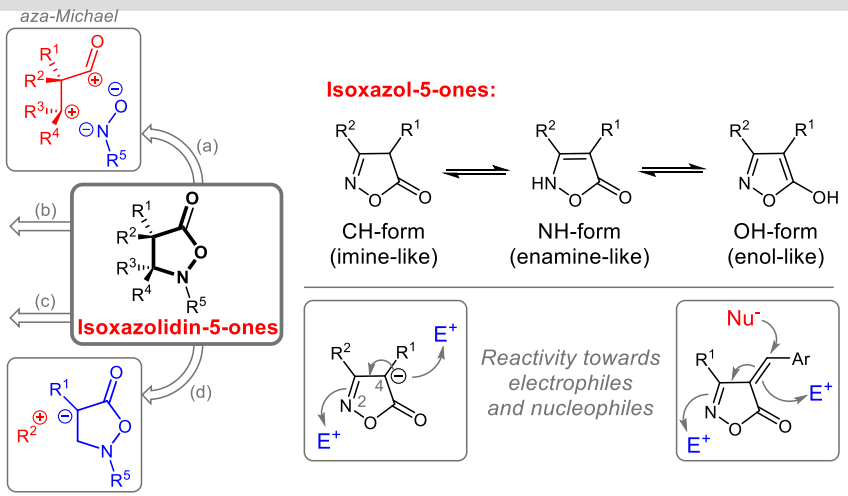

seedlings (compounds 4 and 6) ) $^{1,2,3}$, bacteria (5) ${ }^{4}$ marine sponges $(7)^{5}$ and chrysomeline larvae (8). ${ }^{6}$ Besides the naturally occurring derivatives, a great number of (synthetic) products with very interesting biological activities has been reported (Figure 2). For example, some of them show anti-obesity activity (like compound 9), ${ }^{7}$ are used as anti-cancer agents $(\mathbf{1 0})^{8}$, were employed for the treatment of bladder over-activity in central nervous system (CNS) diseases (11) ${ }^{9}$, or served as HNE (human neutrophil elastase) inhibitors with anti-inflammatory effects (12). ${ }^{10}$ In addition they can show anti-bacterial (13) $1 \mathbf{1 1}$ and p38 MAP (mitogen-activated protein) kinase inhibition activity $\left(\mathbf{1 4},{ }^{12} \mathbf{1 5}^{13}\right)$. Compound $\mathbf{1 6}^{\mathbf{1 4}}$ holds promise as an inhibitor of succinate dehydrogenase and derivatives 17 and $\mathbf{1 8}^{15}$ are promising HDAC (histone deacetylases) inhibitors. Furthermore $\mathbf{1 9 - 2 1}$ and $\mathbf{2 6}^{\mathbf{1 6}}$ show antiandrogen activity as for blefoxatone and toloxatone and some derivatives also find applications as agrochemicals (22-25). $17,18,19,20,21,22$
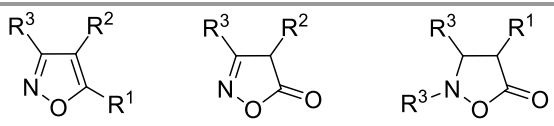

isoxazole, 1 isoxazol-5-one, 2 isoxazolidin-5-one, 3 


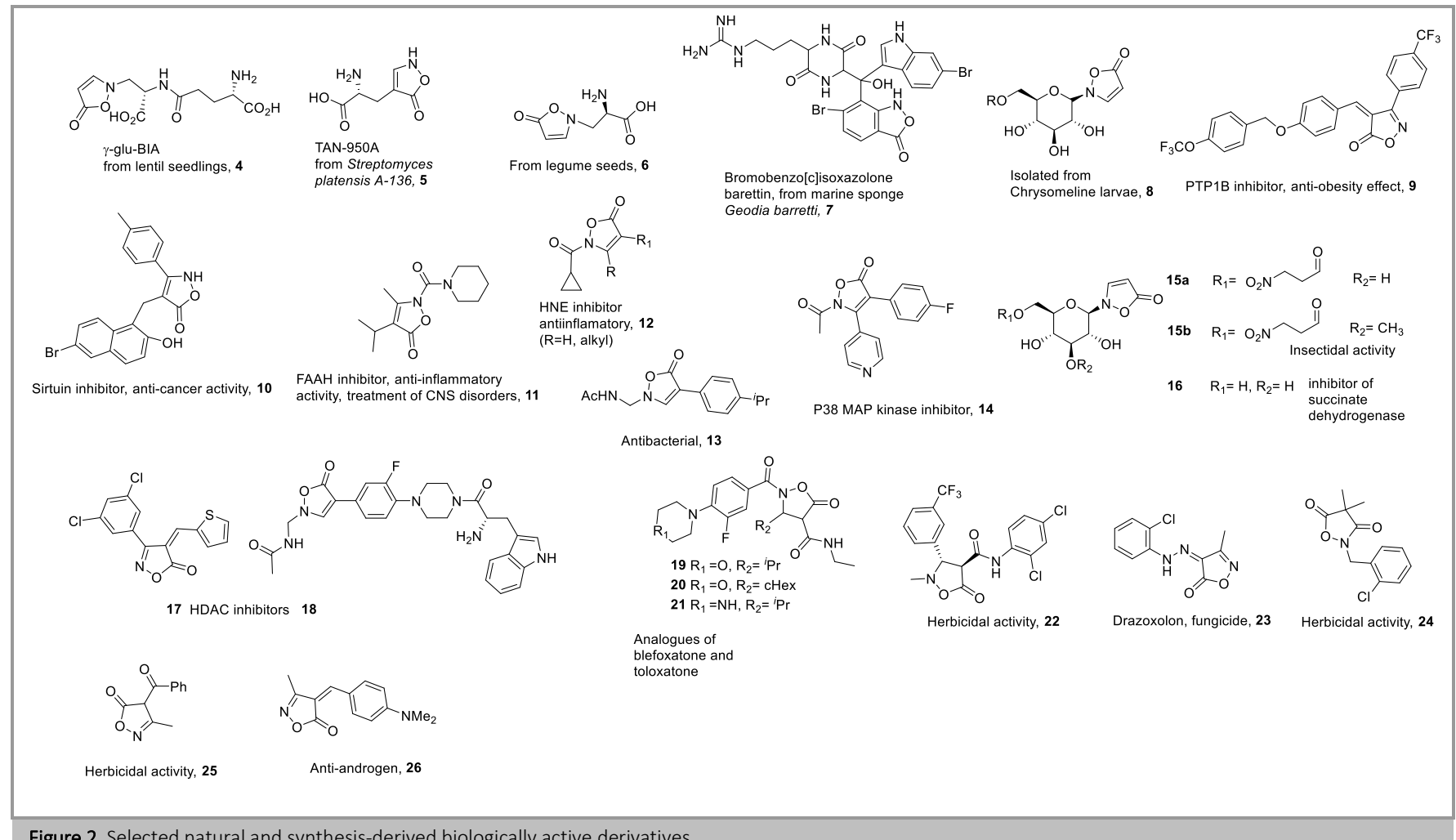

Figure 2 . Selected natural and synthesis-derived biologically active derivatives.

Over the last years the development of asymmetric protocols for the syntheses of chiral isoxazol-5-ones 2 and isoxazolidin-5ones 3 have attracted considerable attention, highlighting several similarities but also some peculiarities between these two related classes of heterocycles. In a recent review, Jurberg et al. have described the general features of isoxazol-5-ones chemistry, focusing mainly on their preparation and further transformations. ${ }^{23}$ Most of this knowledge is also based on the seminal works proposed by the group of Zard. ${ }^{24,25}$ In a complementary review, Brière and coworkers analyzed the properties and the asymmetric construction of the isoxazolidin5 -ones up to the beginning of 2017,26 but it should be emphasized that most of the articles regarding the use of these heterocycles in enantioselective transformation processes have been published subsequently over the last 3-4 years.

Isoxazol-5-ones are characterized by relatively high acidity at C4 because of resonance-stabilization of the resulting carbanion by the carbonyl and the imine group, thus resulting in $\mathrm{p} K$ a values comparable to carboxylic acids. As depicted on Scheme 1, isoxazol-5-ones possess two main nucleophilic sites, N2 and C4, while the exocyclic carbonyl $\mathrm{O}$ atom is usually less reactive. Regioselectivity issues are challenging in this case and depends on several factors, while, in contrast, $\mathrm{N}$-protected isoxazolidin5-ones find applications as $\mathrm{C}$-nucleophiles mainly. For both the heterocycles, the $\mathrm{N}-\mathrm{O}$ bond is relatively weak ${ }^{27}$ and a $\mathrm{CO}_{2}$ molecule can also be eliminated under certain conditions. ${ }^{24,25}$ Accordingly, a variety of transformations have been proposed giving access to more complex isoxazole-derived architectures or furnishing new acyclic building blocks like chiral alkynes and $\beta$-aminoacids. In addition, new heterocycles like piperidines and aziridines can be obtained by ring expansion or contraction, respectively. On the other hand, unsubstituted or 4monosubstituted isoxazol-5-ones show complex tautomers 2 and 27 in equilibrium, due to the acidic $\mathrm{C} 4-\mathrm{H}$ of $\mathbf{2}$ and the relatively high stability of the conjugated $\mathrm{NH}$-form 27a in comparison to aromatic HO-form, 27b (Scheme 1).

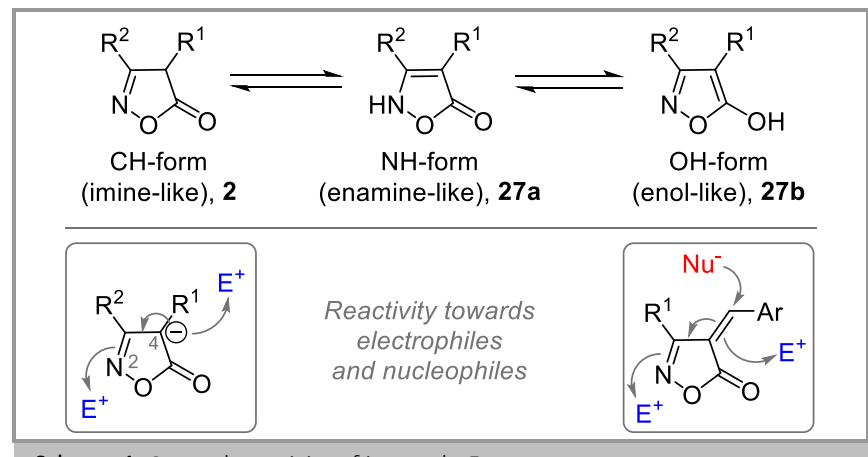

Scheme 1. General reactivity of isoxazole-5-ones.

However, the prevalence of one tautomer strongly depends on the substitution pattern, on the solvent, and on the purification conditions. In most of the cases, mixtures of tautomers can be detected. This can be a limitation, not only for pharmaceutical applications, but it has also practical issues for product characterization, HPLC analysis and determination of diastereomeric and enantiomeric ratios. 
With respect to asymmetric syntheses of isoxazol-5-ones, the currently established methods reflect the above described features and are mainly based on the use of preformed heterocycles. Depending on their substitution patterns, these can serve either as nucleophiles, developing regioselective $\mathrm{N}$ - or C-alkylations (Scheme 1, left side), or as Michael acceptors, even in domino reactions (Scheme 1, right side).

On the other hand, isoxazolidin-5-ones 3 show less diverse inherent reactivity tendencies (Scheme 2). Because of the absence of the imine group they are, first of all, less acidic than isoxazole-5-ones $\mathbf{2}$. In addition, the usually protected nitrogen is not nucleophilic, and thus this class of molecules primarily reacts as $\mathrm{C}$-nucleophiles. As a consequence of these features, the asymmetric synthesis of (functionalized) isoxazolidin-5-ones $\mathbf{3}$ is mainly based on two approaches. The historically wellestablished way to access isoxazolidin-5-ones relies on asymmetric annulation strategies of simple (prochiral) acyclic starting materials (strategies a-c). ${ }^{28}$ In addition, over the last years, several reports described the asymmetric functionalization of racemic isoxazolidin-5-ones (strategy $\mathrm{d}, \mathrm{R}^{2-4}$ $=\mathrm{H}$ ), which currently leads to relatively broad and diverse powerful synthetic strategies to access this valuable heterocyclic platform.

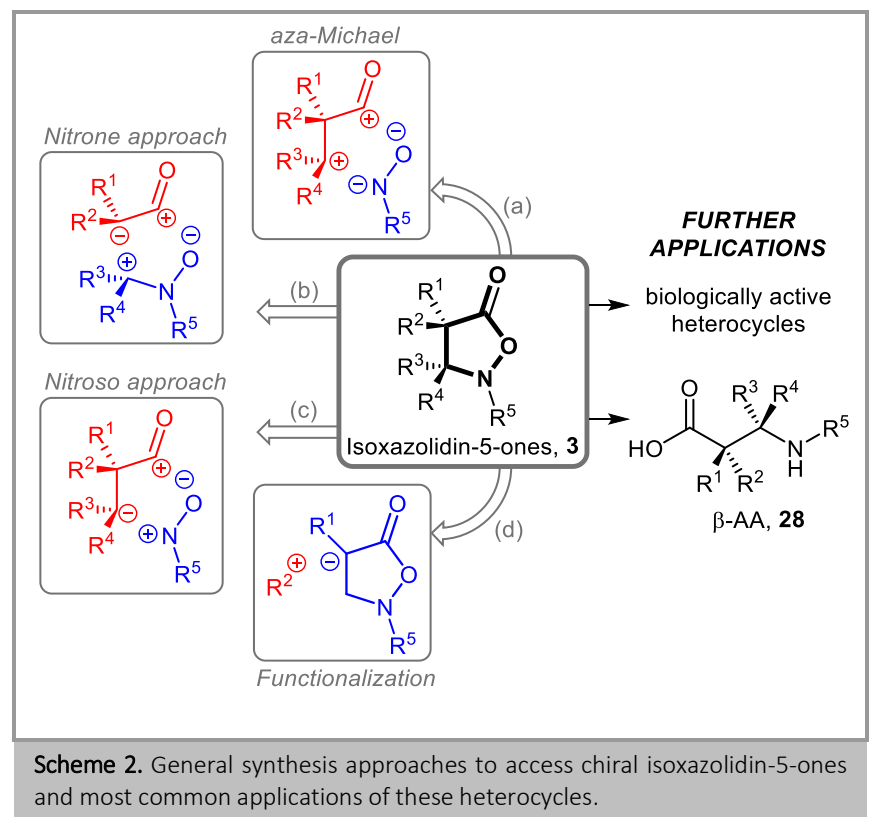

In this review we wish to provide an illustrative (but not encyclopedic) overview about the most relevant recent asymmetric synthetic strategies to access and/or to functionalize isoxazol-5-ones and isoxazolidin-5-ones. All the collected literature has been interpreted according to the above described features and we hope that the present review can inspire investigations toward the development of new methodologies and asymmetric transformations in this field. Therefore, besides discussing the fundamental concepts of the established approaches, we will mainly focus on recent emerging reports from the last few years within the following chapters.

\section{2) Isoxazol-5-ones as C-nucleophiles}

The existence of three potential nucleophilic sites (N2, C4 and the exocyclic carbonyl $\mathrm{O}$ atom in $\mathrm{HO}$-form) usually gives rise to regioselectivity issues (see Scheme 1). ${ }^{29}$ Epimerization and tautomerism limit the applications of the $\mathrm{C}$-alkylations toward the synthesis of derivatives bearing a tetrasubstituted C-4 carbon. However, $\mathrm{N}$-alkylations furnish stable derivatives in enamine-like form with a tertiary nitrogen atom and in these cases both 4-unsubstituted and 4-mono substituted isoxazol-5ones have been utilized. Nevertheless, regioselective asymmetric C-alkylations and $\mathrm{N}$-alkylations have been developed and the respective methodologies will be discussed in the following two sections.

\section{1) Isoxazol-5-ones as C-nucleophiles}

A facile one-pot sequential conjugate addition/dearomative fluorination transformation of isoxazol-5(4H)-ones with nitroolefins and $N$-fluorobenzenesulfonimide (NFSI) has been developed by Ma and coworkers (Scheme 3). ${ }^{30}$ By using an acetylated $\mathrm{N}$-glucoside chiral tertiary amino-thiourea catalyst C1, a series of chiral fluorinated isoxazol-5(4H)-ones $\mathbf{3 1}$ containing one fluorine-substituted quaternary stereocenter was obtained in high yields and with high diastereo- and enantio-selectivities. 


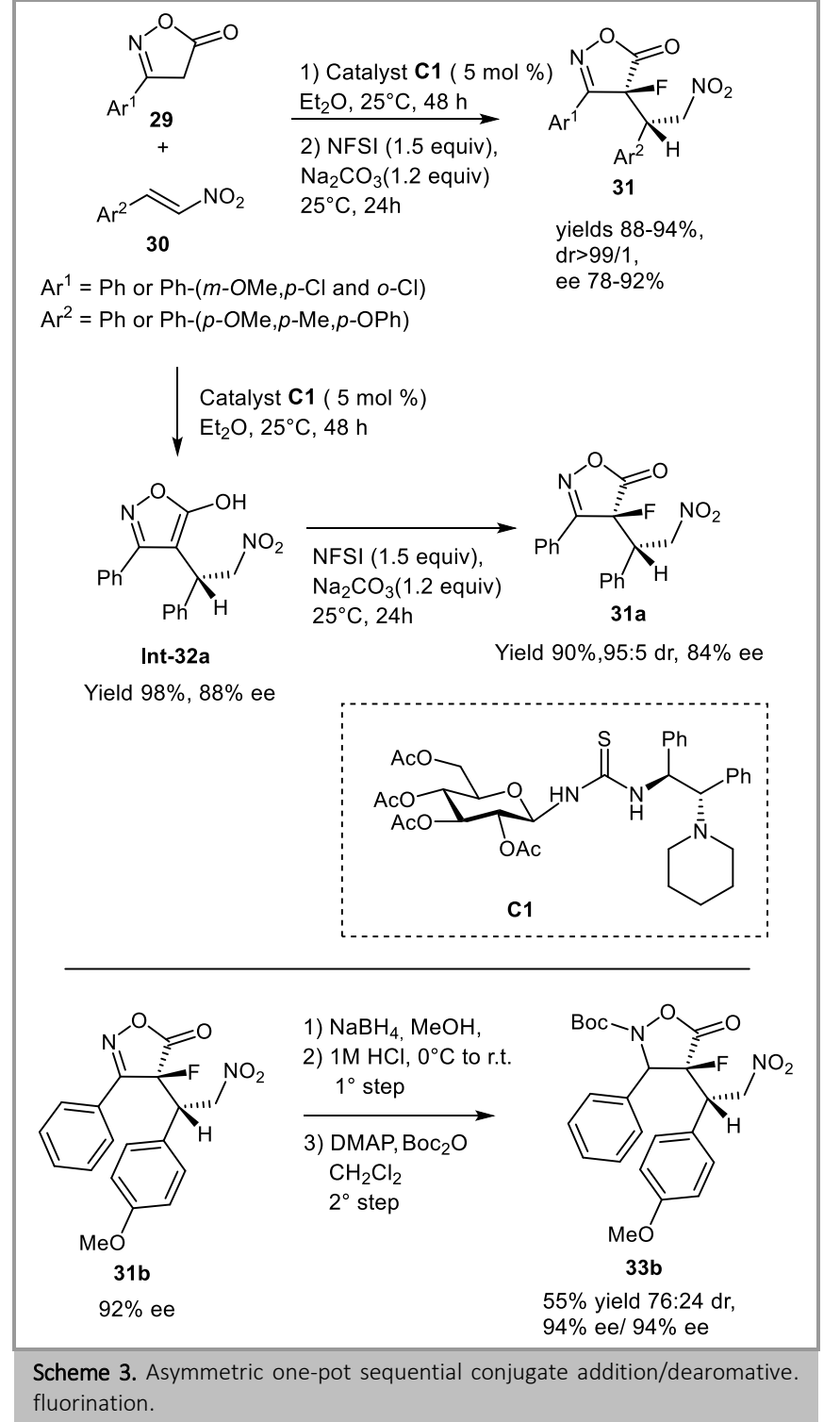

In order to obtain more information about this sequential transformation, several step-by-step control experiments have been performed. In the presence of the tertiary amino-thiourea catalyst C1, compound 29a was transformed into the Csubstituted intermediate Int-32a (Scheme 3), which was isolated in almost quantitative yield with $88 \%$ ee. Subsequent treatment of this intermediate Int-32a with $\mathrm{Na}_{2} \mathrm{CO}_{3}$ and NFSI in the absence of catalyst C1 afforded the dearomatization-fluorination product $\mathbf{3 1 a}$ in $90 \%$ yield with 95:5 dr and $84 \%$ ee. These results indicated that the chiral catalyst not only controls the first step, but also provides stereocontrol in the diastereoselective formation of the $\mathrm{C}-\mathrm{F}$ bond in the subsequent transformation. In addition, sodium borohydride reduction of adduct $\mathbf{3 1 b}$, followed by Bocprotection allowed the synthesis of an isoxazolidin-5-one derivative $\mathbf{3 3 b}$ with three contiguous stereocenters. In this case, only two diastereoisomers have been detected, even though with moderate diastereoselectivity (lower part of Scheme 3). Asymmetric fluorination of 4-substituted isoxazol-5-ones 34 was also achieved by using a bis-cinchona alkaloid catalyst the (DHQ) 2 PYR C2. ${ }^{31}$ A series of derivatives with a fluorinecontaining tetrasubstituted stereocenter $\mathbf{3 5}$ was obtained in good to high yields and with good enantioselectivities as outlined in Scheme 4 (up to $91 \%$ yield, $85 \%$ ee).

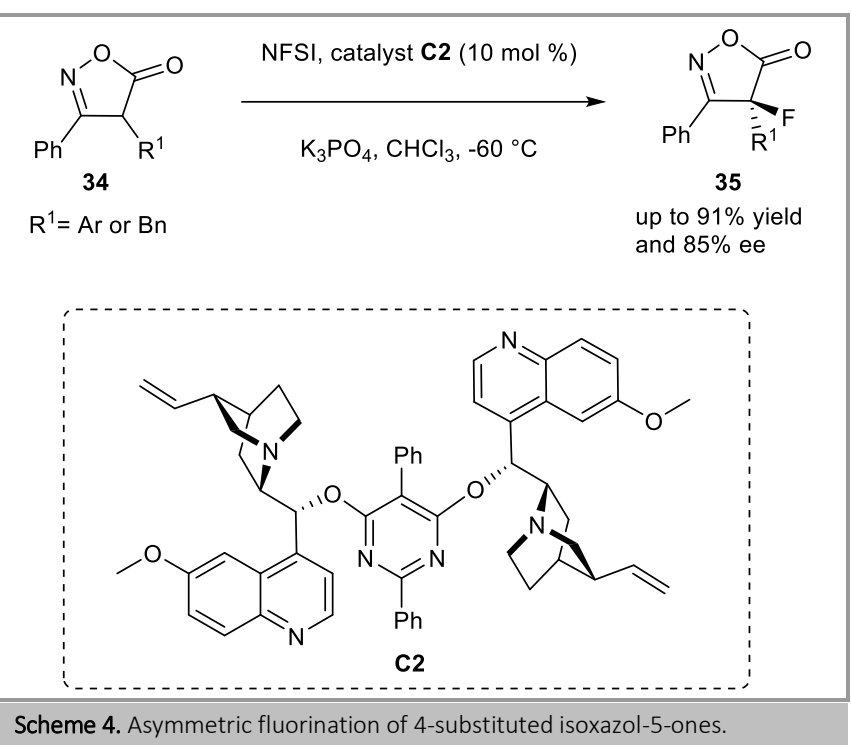

High regio- and enantio-selectivities have been achieved by Peters and co-workers ${ }^{32}$ in the Michael reaction between 4monosubstituted isoxazol-5-ones $\mathbf{3 6}$ with a series of vinyl ketones $\mathbf{3 7}$ in the presence of chiral palladium catalysts $\mathbf{C 3}$, leading to the synthesis of adducts bearing an all-carbon quaternary stereogenic center 38 (Scheme 5). Interestingly, very good yields and high C-regioselectivity were obtained using the bispalladacycle catalyst bearing a pentaphenylferrocene core. The proposed mechanistic models correlate the observed regioselectivity to the sterically demanding pentaphenylferrocene palladacycle catalyst (See Scheme 5). This directs the reactivity in the absence of a base nearly exclusively to the nucleophilic $\mathrm{C}$ atom, while at the same time it allows for high enantioselectivity and TONs up to 1900 . The authors also reported further utilization of the hereby obtained Michael adducts for the asymmetric synthesis of $\mathbf{4 0}$ and $\mathbf{4 2}$ with a tetrahydro-4H-pyrano[3,2-d]isoxazole skeleton. These compounds are a motive of interest for the development of new herbicides (lower part of Scheme 5). 


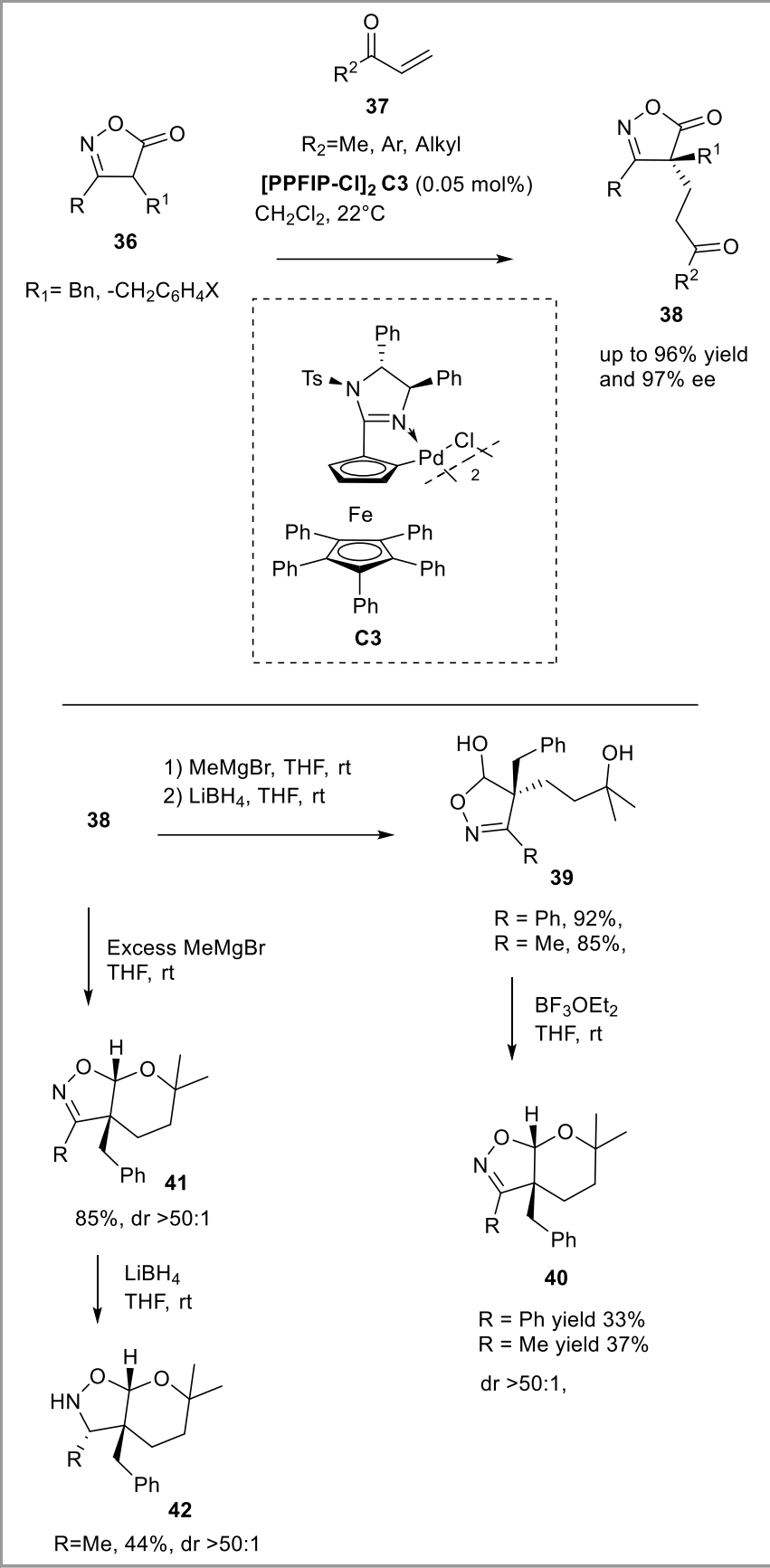

Scheme 5. Asymmetric palladium catalyzed Michael reactions of 4monosubstituted isoxazol-5-ones and synthesis of new tetrahydro- $4 \mathrm{H}$ pyrano[3,2-d]isoxazole.

Later, the same group reported that a combination of chiral irridacycle phosphoramidite catalysts $\mathbf{C 4}$ with $\mathrm{Pd}(\mathrm{OAc})_{2}$ (5 mol\%) as cocatalyst allowed the first regioselective catalytic asymmetric C-allylations of isoxazolinones $\mathbf{4 3}$ (Scheme 6). ${ }^{29}$ The use of the co-catalyst guarantees the observed high $\mathrm{C} / \mathrm{N}$ regioselectivity. Interestingly, this method delivers the linear allylation products $\mathbf{4 5}$, instead of branched ones. This was explained by a sequence of reactions starting from the regioand enantio-selective $\mathrm{N}$-allylation reaction to provide a branched allylic system Int-46, followed by a [3,3]rearrangement with chirality translocation from the allyl part to the heterocycle via a chair-like transition state TS-47 (Scheme $6)$.

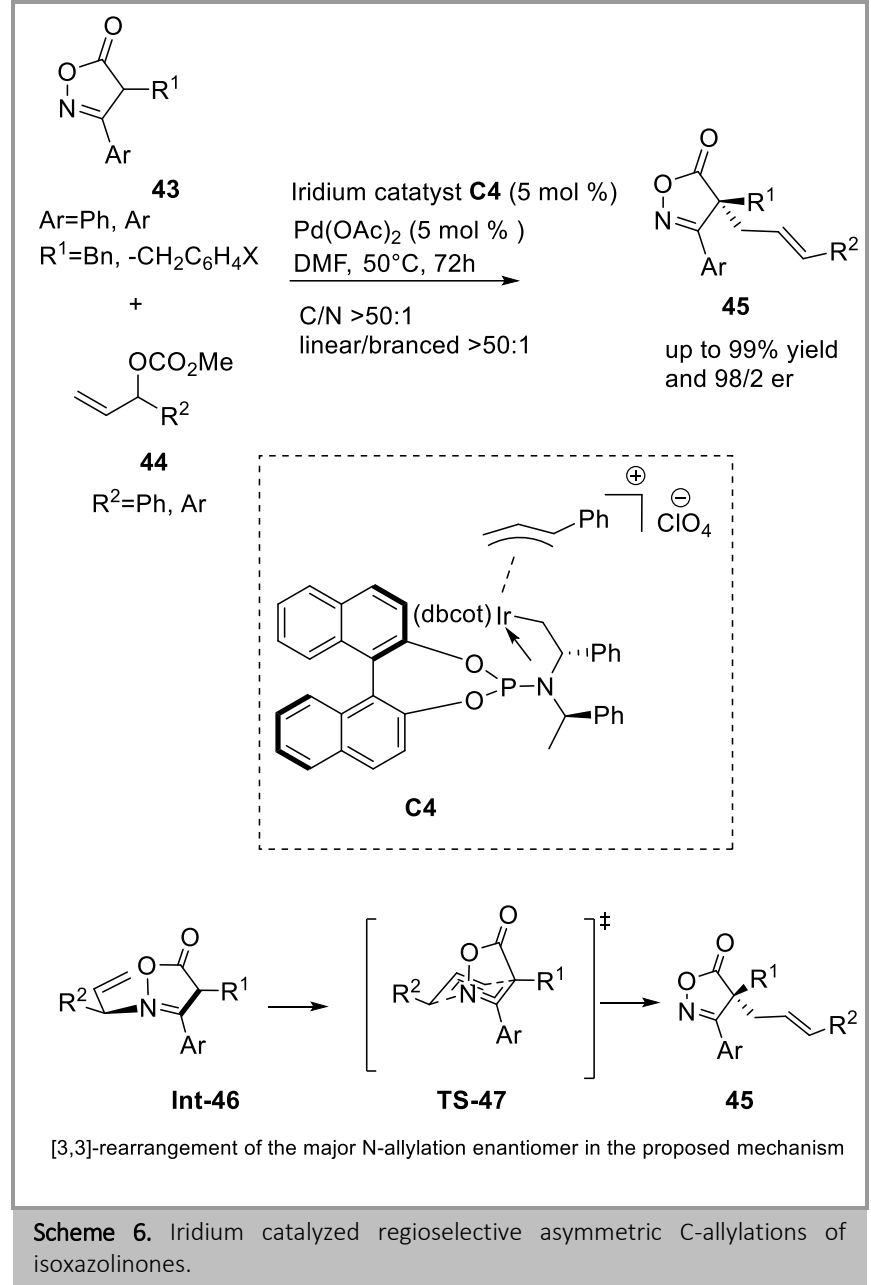

\section{2) Isoxazol-5-ones as $\mathrm{N}$-nucleophiles}

As described independently in 2020 by Pedro, Blay et al. ${ }^{33}$ and by Wang, $\mathrm{Xu}$ and co-workers, ${ }^{34}$ thiourea- and squaramidecontaining Brønsted base bifunctional catalysts C5 and C6 allowed the enantioselective 1,6-aza-Michael addition of isoxazol-5-ones to $p$-quinone methides 49 to give isoxazol-5ones $\mathbf{5 0}$ having a chiral diarylmethyl moiety attached to the nitrogen atom, with fair to good yields and enantiomeric excesses (Scheme 7). The protocol proved to be effective also on gram scale. ${ }^{34}$ Even though both groups reported independently this first enantioselective $\mathrm{N}$-alkylation which is effective even for $\mathrm{C}-4$ unsubstituted isoxazol-5-ones $\left(\mathrm{R}^{2}=\mathrm{H}\right)$, unfortunately no explanation has been given for the observed $\mathrm{N}$-regioselectivity. 


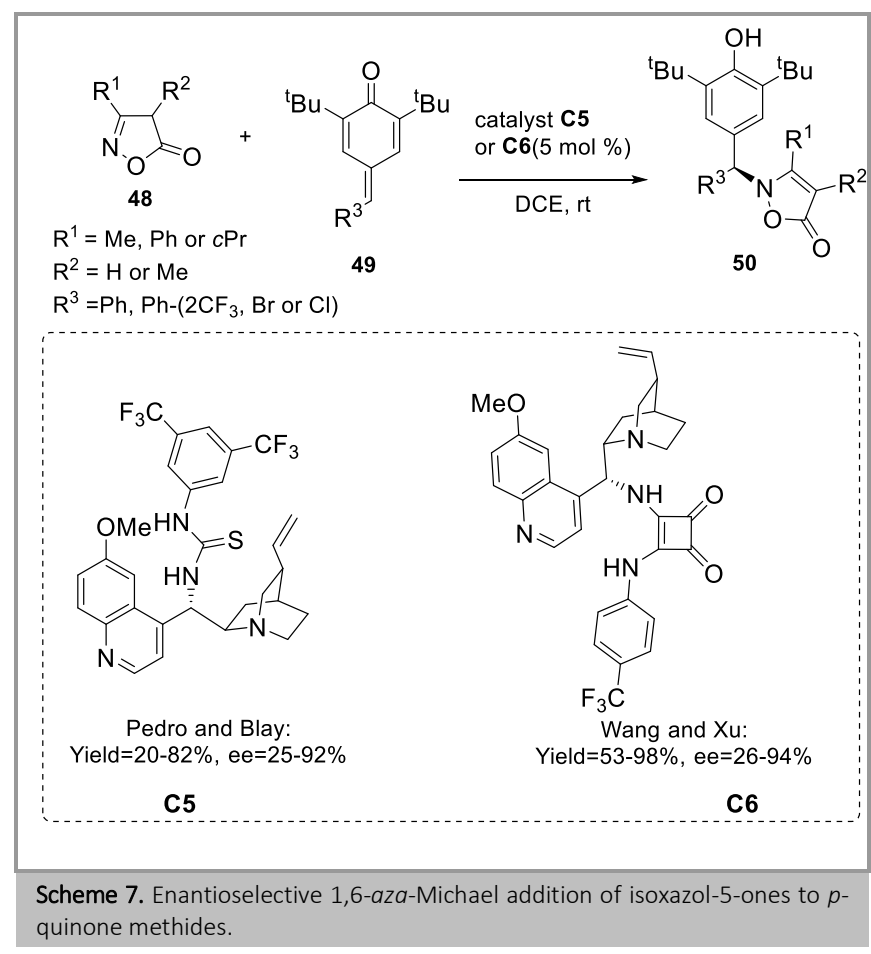

\section{3) Isoxazol-5-ones as C-nucleophiles in cyclization processes}

An asymmetric four-component $(5+1+1+1)$ formal cycloaddition reaction of 3-substituted 2-cyclopentenones $\mathbf{5 1}$ has been developed by Chen, Du and coworkers (Scheme 8). ${ }^{35}$ Activated methylene nucleophiles $\mathbf{5 2}$ and two molecules of aldehydes 53, under chiral primary aminocatalysis, lead to various highly enantioenriched fused and spirocyclic frameworks $\mathbf{5 4}$ with high molecular complexity. Mechanistic studies indicate that the current reaction proceeds via a challenging cascade quintuple Knoevenagel condensation/Michael addition/retro-Michael addition/Michael addition/Michael addition sequence via diverse aminocatalytic modes, with the key intermediate Int-55 as indicated in the lower part of Scheme 8.

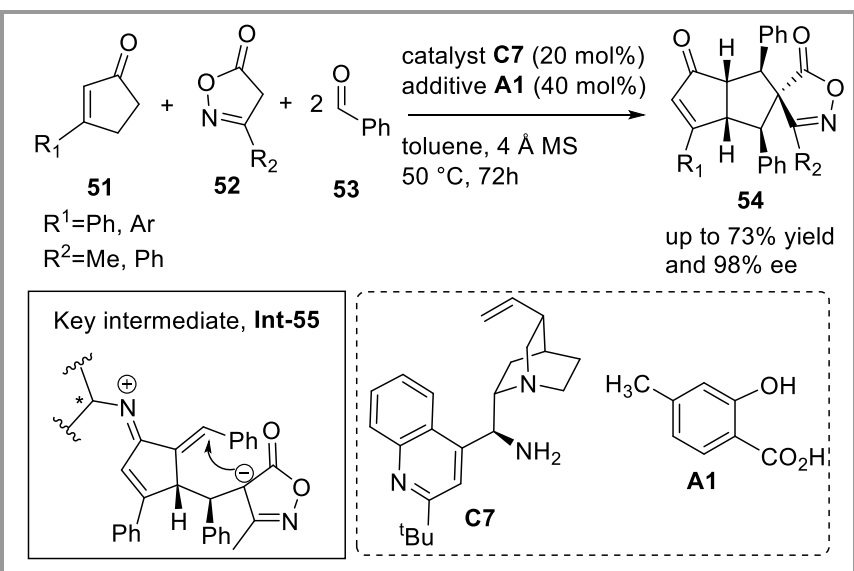

Scheme 8. Asymmetric four-component $(5+1+1+1)$ formal cycloaddition reaction of 3 -substituted 2 -cyclopentenones.

In a recent work $\mathrm{Li}$, Shao and co-workers ${ }^{36}$ have described a very interesting Pd-catalyzed asymmetric allenylic $(4+1)$ formal cycloaddition, leading to the synthesis of 4-spiro isoxazol-5-one derivatives $\mathbf{5 8}$ (Scheme 9). The authors have demonstrated that tuning the $\mathrm{Pd}$ catalyst switched the reactivity toward an unprecedented $(4+3)$ or $(4+1)$ cycloaddition/cross-coupling in the case of pyrazolones, while only $(4+1)$ reaction has been given for isoxazol-5-ones. A possible mechanism is proposed, suggesting two interesting catalytic cycles for the cycloaddition with palladium-butadienyls and the key intermediate Int-59, as described in Scheme 9.

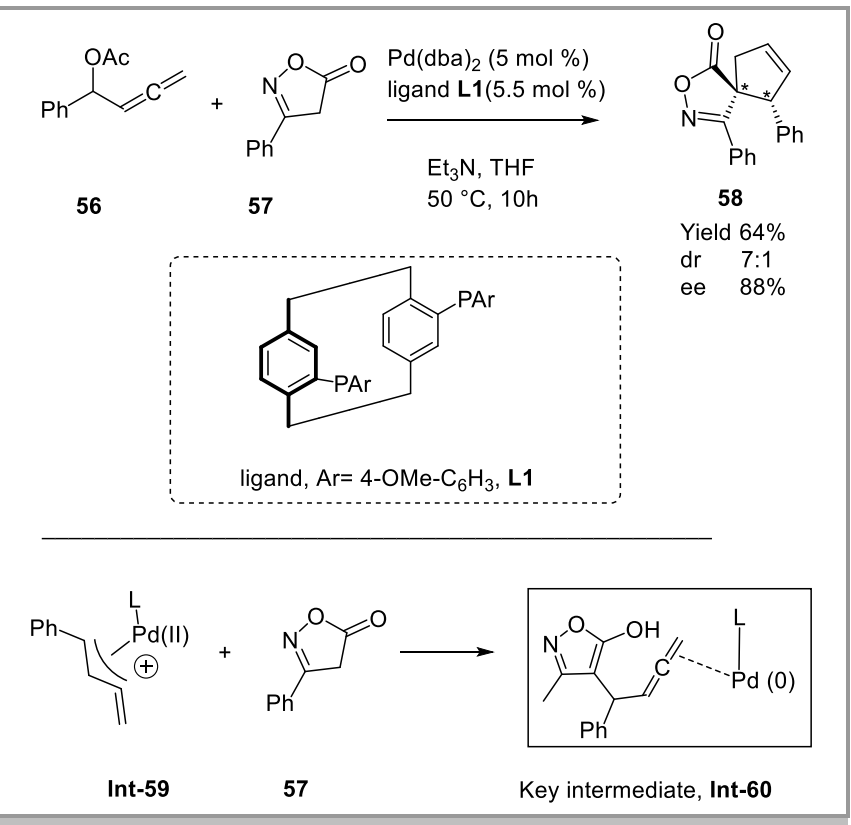

Scheme 9. Pd-catalyzed asymmetric allenylic $(4+1)$ cycloaddition.

\section{1) Asymmetric construction of isoxazolidin-5-ones}

The pioneering (asymmetric) approaches to access isoxazolidin5-ones relied on annulation reactions. First of all, racemic and chiral auxiliary controlled aza-Michael type additions of substituted (chiral) hydroxylamine derivatives to various Michael acceptors were reported almost 40 years ago by Baldwin's group.28a Over the years, this methodology allowed access to a variety of chiral $\beta$ - or $\alpha, \beta$-substituted isoxazolidin-5ones, but the first asymmetric reports essentially relied on the use of chiral auxiliaries. ${ }^{37}$ In the early 2000 s, a variety of versatile asymmetric catalytic strategies were reported.38,39,40,41 Sibi's group was the first to developed a powerful chiral Mgcomplex-catalyzed protocol to facilitate enantioselective azaMichael sequences by adding $N$-substituted hydroxylamines $\mathbf{6 2}$ to pyrrolidinone-containing amide Michael acceptors 61 . This strategy gave access to highly enantioenriched $\beta$-substituted isoxazolidin-5-ones 63 as shown in Scheme 10.38 


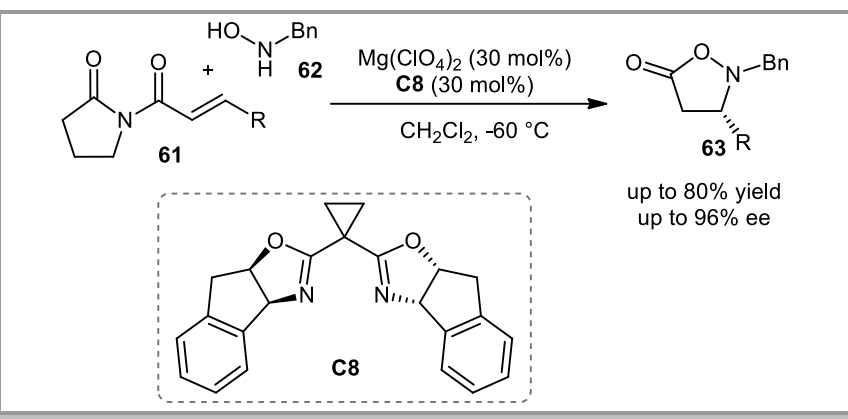

Scheme 10. First catalytic asymmetric isoxazolidin-5-one synthesis report by Sibi's group.

The following years then witnessed the introduction of a variety of alternative organocatalytic approaches. In this context impressive methods making use of chiral phosphoric acid catalysis, ${ }^{39}$ chiral Brønsted base-mediated approaches, ${ }^{40}$ and chiral iminium activation were introduced. ${ }^{41}$ The majority of these reports were discussed in much detail in a recent review. ${ }^{26}$ Iminium activation of $\alpha, \beta$-unsaturated aldehydes with chiral secondary amine catalysts is also a very powerful methodology to obtain this heterocyclic platform (Scheme 11). ${ }^{41}$ Hereby the classical Hayashi-Jørgensen catalyst $\mathbf{C 9}$ turned out to be well-suited and could even be used in a one-pot two-step protocol where the enal $\mathbf{6 5}$ was accessed in situ by cross metathesis and then directly underwent the cyclization reaction with $\mathbf{6 4}$, as demonstrated by Ge's group. ${ }^{41 c}$ More recently, immobilized catalyst derivatives like C10 were also successfully used by Pericas and co-workers with high selectivities in batch and flow. ${ }^{41 \mathrm{~d}}$ Compared to other approaches, this iminium strategy is also very interesting as the primarily obtained enantioenriched isoxazolidin-5-ols $\mathbf{6 6}$ have not only been oxidized to isoxazolidin-5-ones $\mathbf{6 7}$, but can also be directly utilized to access other molecules of interest, as demonstrated by Ge's group who synthesized sitagliptin phosphate monohydrate via such a strategy. ${ }^{41 e}$

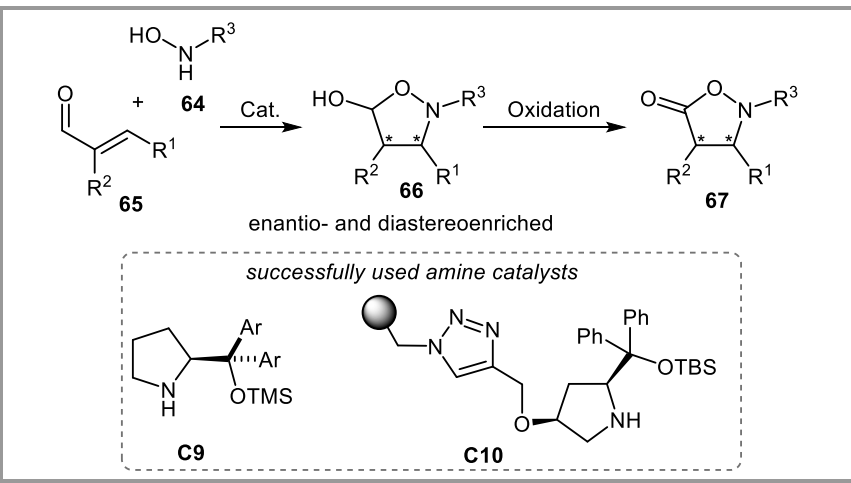

Scheme 11. The general concept of using iminium catalysis to control azaMichael type-cyclizations to access compounds 66 (and 67 successively).

The addition of N-nucleophiles to Morita-Baylis-Hillman (MBH) carbonates 68 can be considered as a powerful alternative to classical aza-Michael addition chemistry and, in 2012, Chen and co-workers nicely demonstrated that such a strategy allows to access the chiral spiroisoxazolidin-5-one $\mathbf{7 1}$ with high enantioselectivity (Scheme 12-A). ${ }^{42}$ In their organocatalytic approach they found that the $\beta$-isocupreidine derivative C11 allows for high yield and enantioselectivity in the addition of the carbamate derivative to the $\mathrm{MBH}$ carbonate $\mathbf{6 8}$ (giving the

formal aza-Morita-Baylis-Hillman product 70). This compound can then be cyclized to the $\alpha$-methylene isoxazolidin-5-one $\mathbf{7 1}$ without loss of optical purity by desilylation, followed by basemediated transesterification. Similarly, Vesely and co-workers have recently shown that such a strategy afforded the chiral isoxazolidin-5-ones $\mathbf{7 3}$ with reasonable levels of enantioselectivity (Scheme 12). ${ }^{43}$ In their approach $\beta$ isocupreidine (C12) turned out to be the catalyst of choice to control the $\mathrm{N}$-addition of carbamate 69 to MBH carbonates 72, followed by desilylation and a $\mathrm{Bu}_{2} \mathrm{SnO}$-mediated transesterification to access the $\alpha$-methylene isoxazolidin-5-one 73 (Scheme 12-B).

A) Addition to oxindole-base MBH-carbonates<smiles>C=C(C(C)=O)C1(OC(C)=O)C(=O)N(C)c2ccccc21</smiles>

$68 \mathrm{Me}$

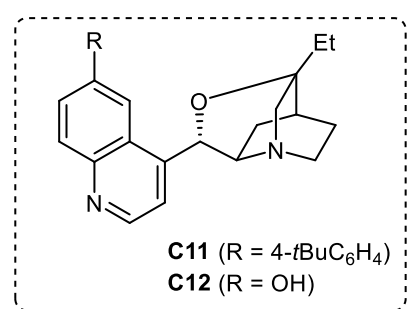

$0^{\circ} \mathrm{C}$

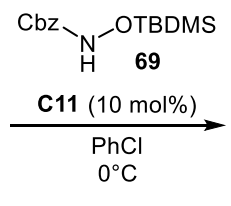

$$
-
$$

B) Additon to $\mathrm{MBH}$-carbonates 72

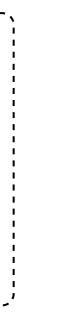

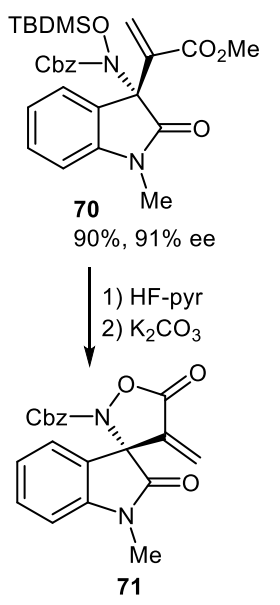

no loss in ee

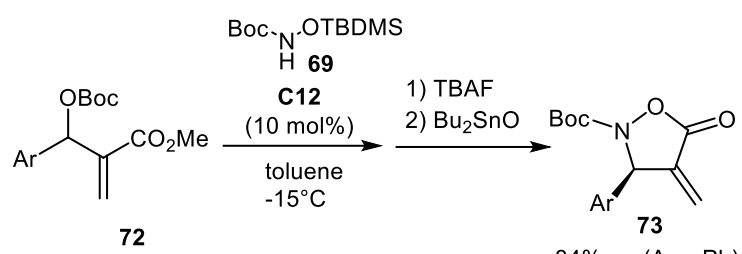

$84 \%$ ee $(\mathrm{Ar}=\mathrm{Ph})$

Scheme 12. Organocatalytic two-step isoxazolidin-5-one synthesis starting from Morita-Baylis-Hillman carbonates.

Very recently (Scheme 13), ${ }^{44}$ utilizing Meldrum's acid 76,45 Brière and co-workers extrapolated the multicomponent Knoevenagel-aza-Michael-Cyclocondensation reaction to readily available hydroxamic acids $\mathbf{7 5}$ derived from naturally occurring $\alpha$-amino acids $(\alpha \mathrm{AA})$. The thus obtained novel isoxazolidin-5-ones $\mathbf{7 7}$ proved to be useful platforms for the diversity-oriented synthesis of $\alpha / \beta$-dipeptide derivatives $\mathbf{7 8}$. The likely diastereoselective aza-Michael reaction, taking place onto the highly electrophilic in situ formed alkylidene Meldrum's acid intermediate Int-79,45 turned out to be rather sensitive to the nature of the employed catalytic Brønsted base $\left(\mathrm{R}_{3} \mathrm{~N}\right)$, among them the (DHQ) ${ }_{2}$ PHAL C13 displayed the best outcome along with a significant match effect during a double induction process. 


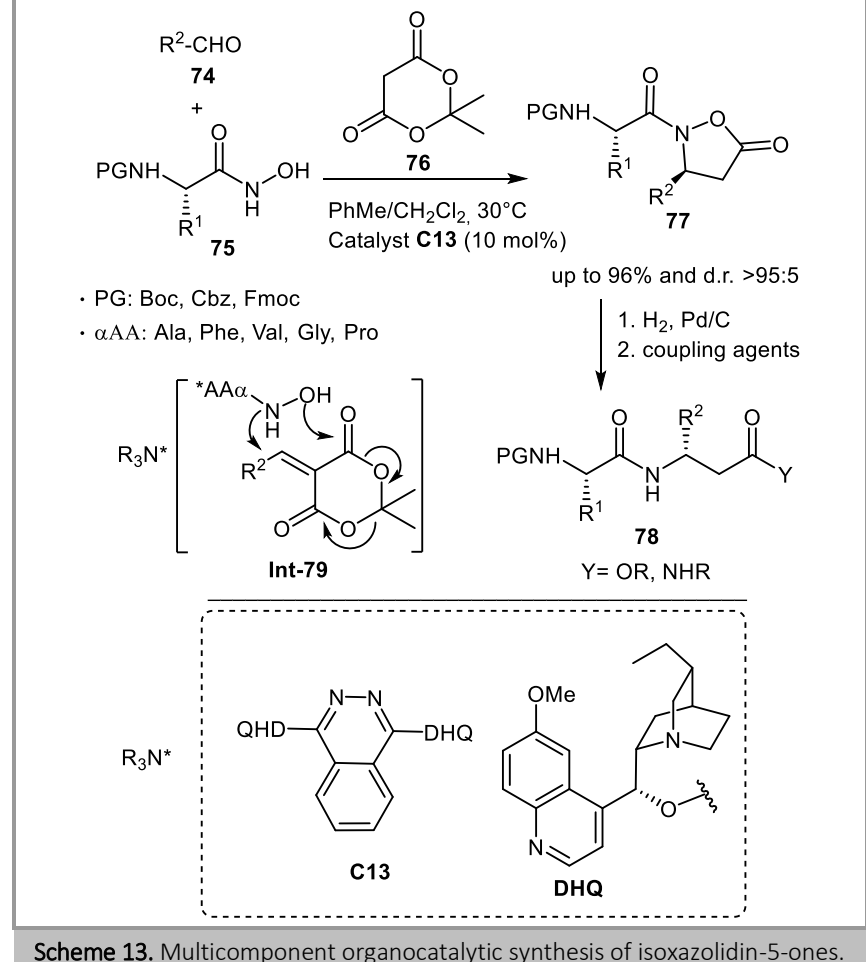

Scheme 13. Multicomponent organocatalytic synthesis of isoxazolidin-5-ones.

A rather general approach to access highly functionalized $\beta$ substituted isoxazolidin-5-ones $\mathbf{8 3}$ relies on formal $(3+2)$ annulation reactions of nitroso compounds with suited three carbon building blocks.46,47 The groups of Zhang and Ying and, subsequently, Rodriguez and Coquerel achieved the transformation of nitroso compounds based on the use of carbene precatalysts which activate enals $\mathbf{8 0}$ to perform $(3+2)$ annulations via the formation of Breslow intermediates Int-82, (Scheme 14). ${ }^{46}$

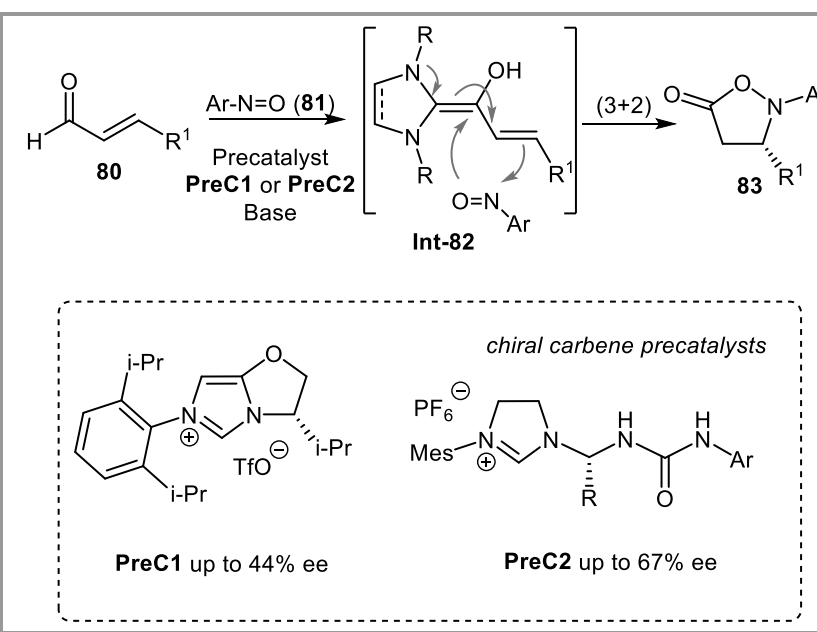

Scheme 14. NHC-catalyzed formal $(3+2)$ cycloaddition of nitroso reagents to access $\beta$-substituted isoxazolidin-5-ones.

Alternatively, 1,4-dicarbonyl compounds like oxindole $\mathbf{8 4}$ were successfully used for nitroso aldol-esterification cascades under bifunctional thiourea catalysis to access the spirooxindoles 85 straightforwardly and with high enantioselectivities (Scheme 15). ${ }^{47}$ Surprisingly however, to the best of our knowledge, no further developments of this concept have been reported anymore.

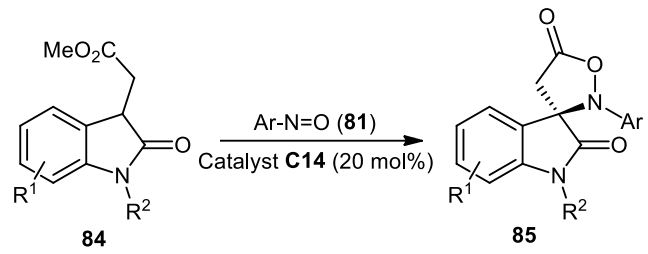

up to $94 \%$ ee

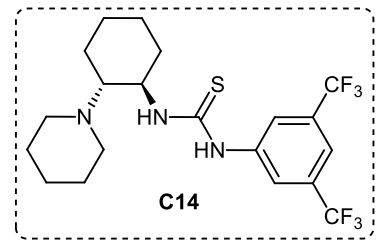

Scheme 15. A Brønsted base-catalyzed formal $(3+2)$ cycloaddition of nitroso reagent to access $\beta$-substituted isoxazolidin-5-ones.

On the other hand, the use of nitrones as 1,3-dipolar building blocks in combination with suited two carbon synthons has been investigated in much details over the last years. ${ }^{48,49}$ Since 2003, first reports by Shindo, Florio and others relied on diastereoselective approaches which led to high stereoselectivities with a limited scope however.48

Over the last years, the group of Brière tackled the organocatalytic and asymmetric synthesis of chiral enantioenriched isoxazolidin-5-ones via a nitrone pathway starting from Meldrum's acid $\mathbf{7 6}$ and derivatives. ${ }^{49}$ Especially, by utilizing the substituted Meldrum's acid 86 and $N$-hydroxysulfone 87, under basic and biphasic conditions, a straightforward synthesis of $\alpha$-substituted isoxazolidin-5-ones 88 occurred in high yields and with goods enantioselectivities (Scheme 16). It has been proposed that, upon a phase-transfer catalytic protocol, the Meldrum's acid anion Int-89 would undergo a formal $(3+2)$ cycloaddition to the in situ generated nitrone. Then, this domino sequence would be terminated by the enantioselective protonation reaction of the corresponding enolate intermediate, thanks to the bifunctional cinchonaderived catalyst C15. It is worth noting that $\alpha$-substituted isoxazolidin-5-ones 88, after hydrogenolysis of the $\mathrm{N}-\mathrm{O}$ bond, afford an access to $\beta^{2}$-AA, a highly versatile but difficult to access class of chiral $\beta$-AA (further applications of these targets to access $\beta^{2,2}$-AA will be discussed in the next chapter). 


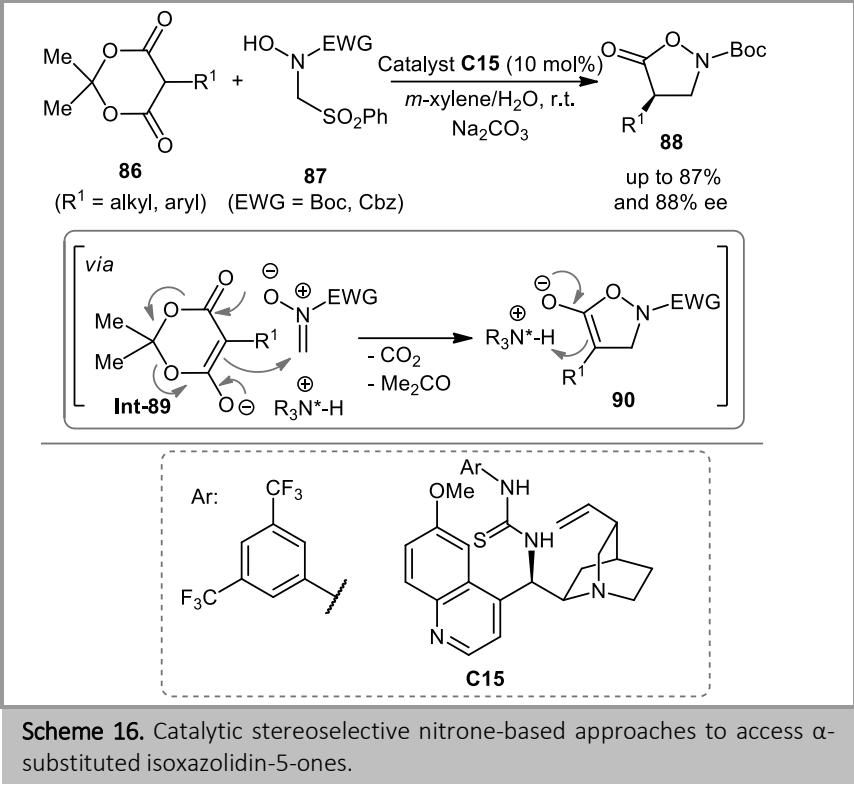

\section{2) Enantioselective}

$\alpha$-functionalizations

of isoxazolidin-5-ones

Besides building the isoxazolidin-5-one motif via asymmetric cyclization strategies (as outlined above), the enantioselective modification of (racemic) isoxazolidin-5-ones 88, i.e. via $\alpha$ functionalization approaches, became a powerful methodology over the last years. ${ }^{50,51,52,53,54}$ The thereby accessed chiral products 91 not only serve as versatile masked $\beta^{2,2}$-amino acid derivatives 92 (Scheme 17-A), but may also undergo further heterocycle forming reactions as demonstrated by Noda and Shibasaki very recently (Scheme 17-B). ${ }^{55}$

$$
\text { A. Asymmetric syntheses of } \beta^{2,2} \text {-AA }
$$

\section{B. Electrophilic amination and $\mathrm{C}-\mathrm{H}$ insertion reactions}

$$
\text { C-H insertion }\left(R^{2}=\text { alkyl) Electrophilic amination }\left(R^{2}=A r\right)\right.
$$

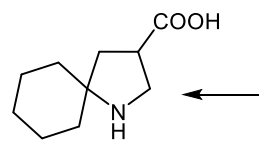

94

$\left(\mathrm{R}^{2}=\mathrm{Cy}, \mathrm{R}^{1}=\mathrm{H}\right)$

Scheme 17. (A) Isoxazolidin-5-ones to access (masked) $\beta^{2,2}-A A$ and (B) to access cyclic $\beta$-amino acids via electrophilic amination or $\mathrm{C}-\mathrm{H}$ activation methods.

Brière and co-workers were the first to demonstrate that $\alpha$ alkylated isoxazolidin-5-ones $\mathbf{8 8}$ can undergo highly enantioselective $\alpha$-functionalization reactions. ${ }^{50}$ By using the commercially available Maruoka ammonium salt C16 as catalyst ${ }^{56}$ they established a straightforward protocol for the highly enantioselective $\alpha$-sulfanylation of $\mathbf{8 8}$ with the phthalimide-based S-transfer reagents 96 (Scheme 18-A). In this report, they also demonstrated that the chiral products may easily undergo ring-opening via reductive $\mathrm{N}-\mathrm{O}$ bond cleavage, thus giving access to $\alpha$-sulfanylated $\beta^{2,2}$-AA. Very interestingly, a broad variety of other commonly established chiral ammonium salt catalyst were tested as well, ${ }^{57}$ but none of them allowed for any noteworthy selectivity. This exclusive potential of the Maruoka catalysts C16 (and C17 as well) to control the asymmetric ammonium salt-catalyzed transformations of compounds $\mathbf{8 8}$ was also described in other recent investigations (vide infra), but the exact reasons for this effect remain yet unknown. Very recently, ${ }^{52}$ the groups of Della Sala and Aleman as well as the groups of Cahard and Waser independently reported the asymmetric $\alpha$-trifluoromethylthiolation of $\alpha$-alkyl and $\alpha$-aryl-substituted substrates $\mathbf{8 8}$ using chiral ammonium salts C16 or C17 (Scheme 18-B). Further transformations of the products 100 like ring-opening reactions, direct KAHA $(\alpha-$ ketoacid-hydroxylamine)-type ligations ${ }^{58}$ or S-oxidations to sulfone were successfully carried out, thus demonstrating the overall potential of this catalysis concept to access versatile chiral target molecules from a simple heterocyclic platform.

$$
\begin{aligned}
& \text { A. } \alpha \text {-Sulfanylation } \\
& \left(\mathrm{R}^{1}=\text { alkyl }\right)
\end{aligned}
$$

$\alpha$-Trifluoromethylthiolation

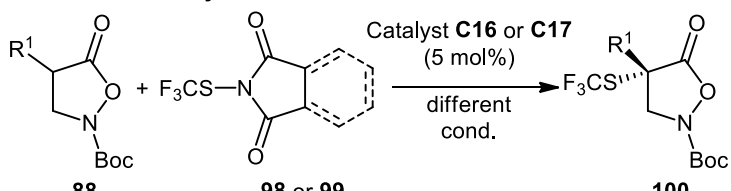

$\left(\mathrm{R}^{1}=\right.$ alkyl, aryl)
98 or 99 up to $91 \%$ yield up to $96 \%$ ee

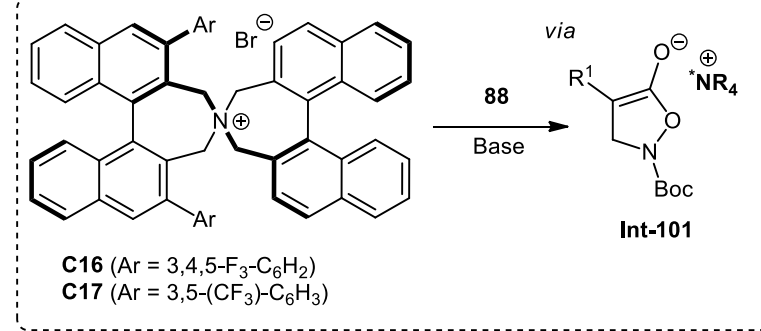

Scheme 18. Quaternary ammonium salt catalyzed asymmetric $\alpha$-sulfanylation reactions.

With respect to further $\alpha$-heterofunctionalization reactions of compounds 102, it is fair to say that this approach is still in its infancy, and apart from the $\alpha$-sulfanylation and $\alpha$ trifluoromethylthiolation approaches only one example of an asymmetric $\alpha$-amination reaction under asymmetric ammonium salt catalysis was reported by Brière so far (Scheme 19).51a 


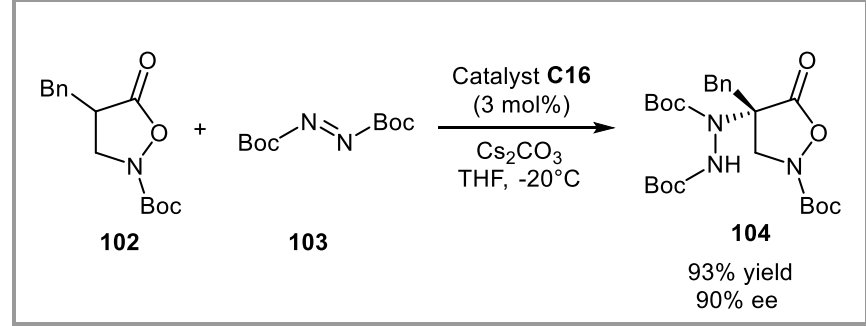

Scheme 19 . Quaternary ammonium salt catalyzed asymmetric $\alpha$-amination reaction.

Asymmetric C-C bond forming reactions of pronucleophiles $\mathbf{8 8}$ were carried out under a variety of different catalytic conditions over the last 2-3 years. ${ }^{51,53,54}$ First, enantioselective conjugate addition reactions were investigated. The Michael acceptors 105-107 were found to be well tolerated under chiral ammonium salt catalysis (again with catalysts C16 or C17), as demonstrated by Brière's group and Waser's group (Scheme 20). ${ }^{51}$ Remarkably, while the addition of $\mathbf{1 0 2}$ to acrylates $\mathbf{1 0 5}$ and MBH-carbonates 106 required around 3-5 mol\% of the catalysts, the reaction with para-quinone methides 107 could be carried out with as low as 20 ppm of the catalyst C16, which represents one of the lowest catalysts loadings reported in asymmetric organocatalysis so far.

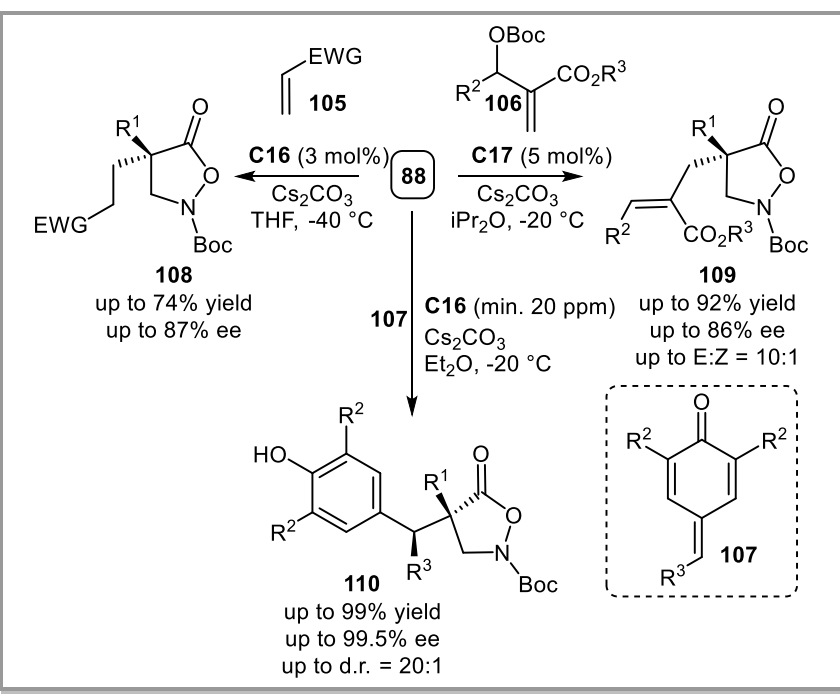

Scheme 20. Asymmetric conjugate additions of pronucleophiles 1 under asymmetric phase-transfer catalysis.

Noda and Shibasaki recently investigated asymmetric Mannich type reactions of compounds $\mathbf{8 8}$ (Scheme 21). ${ }^{54}$ The addition of 88, having an aryl $\left(\mathrm{R}^{1}\right)$ pendant, to the acceptor $\mathbf{1 1 1}$ was possible by using the commercially available organocatalyst C18, acting as a Brønsted base. In a single case,54a the authors also demonstrated that simple quinidine is also able to catalyze the asymmetric addition of $\mathbf{8 8}$ to nitrostyrene as Michael acceptor. On the other hand, the Mannich reaction with simple aldimines 112 and platform 88 with an alkyl ( $\left.\mathrm{R}^{1}\right)$ pendant, likely less acidic, required a very carefully optimized combination of $\mathrm{AgPF}_{6}$ with ligand $\mathbf{L 2}$, a diphosphineoxide additive and a phenolate base to achieve good reactivity and ees. Unfortunately, however, the obtained diastereoselectivities were found to be relatively low in this last case..$^{54 b}$

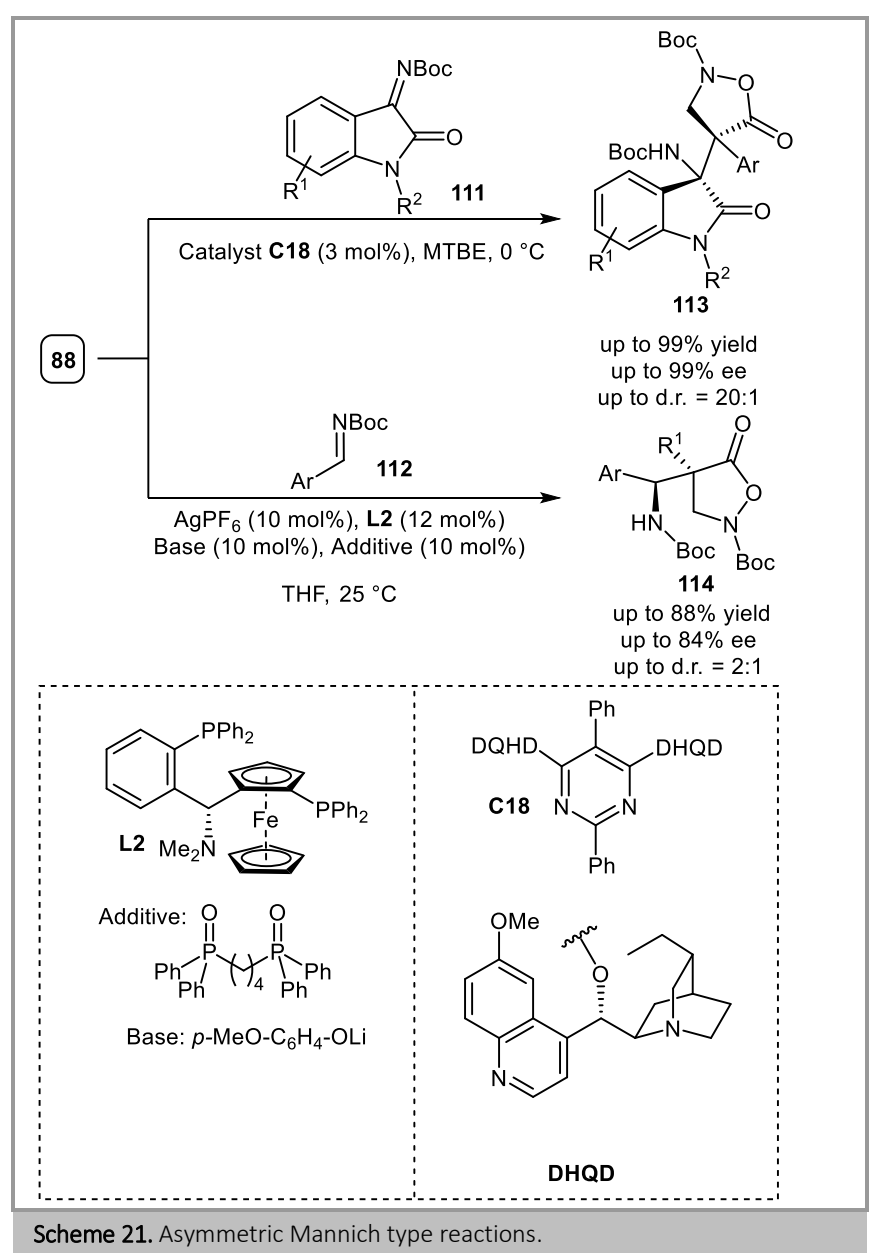

In 2018, Noda and Shibasaki also introduced a highly enantioselective decarboxylative Pd-catalyzed $\alpha$-allylation protocol by starting from the racemic allyl esters 115 (Scheme 22). ${ }^{53 a}$ In this report, they first demonstrated that isoxazolidin5-ones can be directly employed in KAHA-type ligations. ${ }^{58}$ Since then, this methodology emerged as a very powerful strategy to directly access $\alpha / \beta$-dipeptides from this heterocyclic platform and it was recently demonstrated to be rather generally possible for other isoxazolidin-5-one derivatives $\mathbf{1 1 6}$ as well. ${ }^{51,5252 b, 54}$

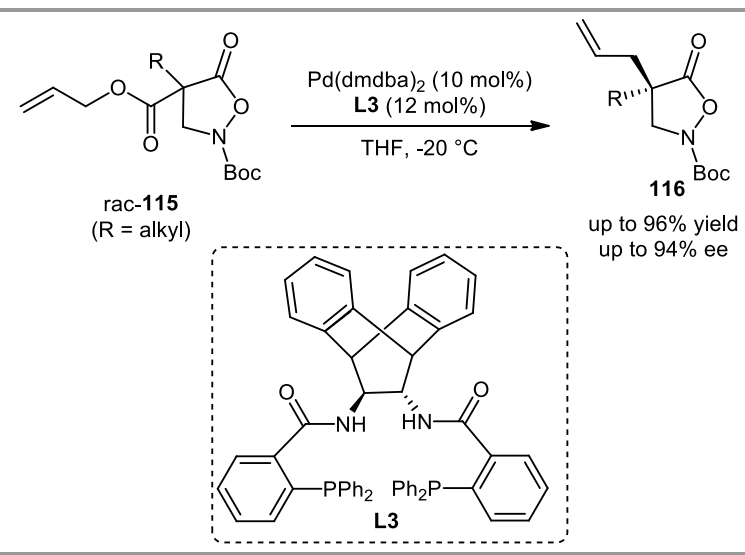

Scheme 22. Asymmetric decarboxylative $\alpha$-allylation approach B.

The intermolecular Pd-catalyzed $\alpha$-allylation of $\alpha$-aryl isoxazolidin-5-ones was shortly after described by Arseniyadis and Cossy, giving access to a broad variety of highly 
functionalized derivatives 118 with excellent selectivities as well via Int-119 (Scheme 23). ${ }^{53 b}$

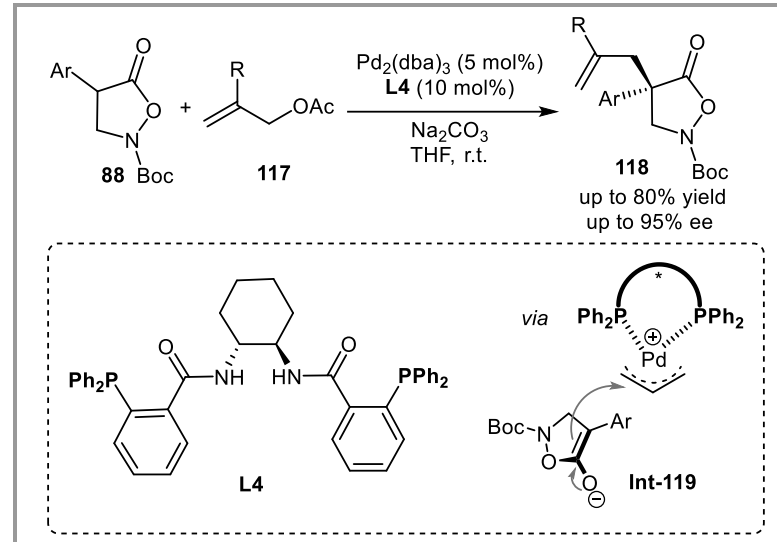

Scheme 23. Asymmetric $\alpha$-allylation approaches.

\section{4) Arylideneisoxazol-5-ones in conjugated addition}

Despite the high reactivity of arylideneisoxazol-5-ones in conjugated additions, ${ }^{23}$ the obtained Michael adducts suffer from tautomeric equilibria according to Scheme 1, as for isoxazol-5-ones mono-substituted at C-4 position. Therefore, a relatively limited number of applications has been described in this field. Most of them are directed toward the synthesis of derivatives with a tetrasubstituted carbon, exploiting in these cases the reactivity of the enolate intermediate in domino reactions ${ }^{59}$ or otherwise the selective in situ entrapping/protection of the $\mathrm{NH}$-tautomer of the respective Michael adducts is necessary. ${ }^{60}$ In addition, the obtaining of complex molecular architectures has also been of great utility in further transformations of the Michael adducts allowing for example an entry to versatile alkynes. ${ }^{61}$ Although a great number of synthesis methodologies of arylideneisoxazol-5-ones have been reported $23,59-66$ and they have been sometimes represented with $E$-configuration, $Z$ isomers are reported to be more stable.62 X-ray structures confirm this outcome for a few derivatives. 61,62

In one of the first reports, an efficient organocatalytic diastereoand enantioselective cascade reaction between 3-isothiocyanato oxindoles 120 and unsaturated isoxazolones 121 has been described by Yuan ${ }^{59}$ and co-workers in the presence of commercially available quinine as catalyst C19. This process consisting, of a domino Michael addition / cyclization sequence, has allowed the construction of spirocyclic oxindole derivatives 122 bearing two spiro quaternary centers and three consecutive stereocenters in high to excellent yields with moderate to high diastereo- and enantio-selectivities (Scheme 24).

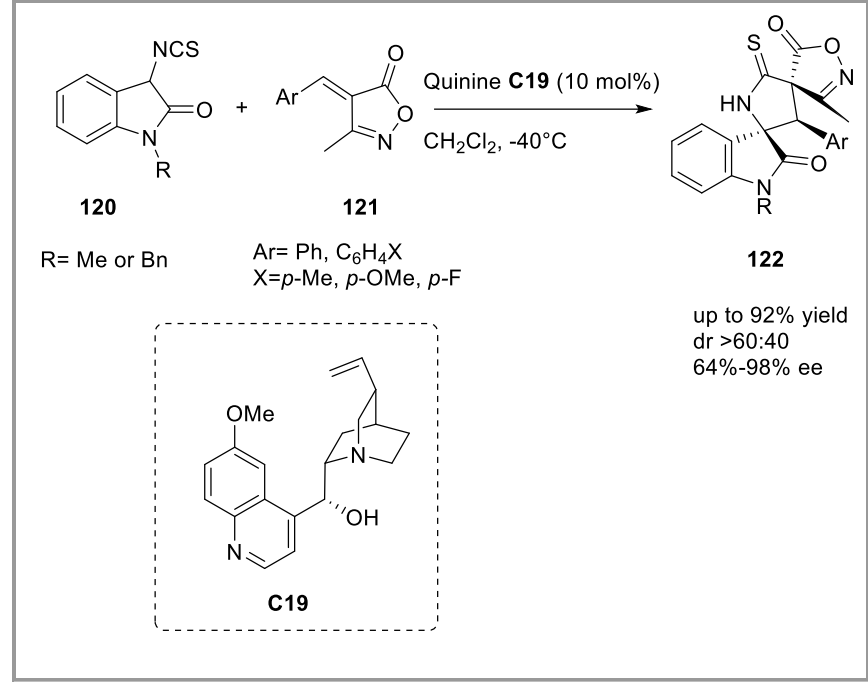

Scheme 24. Diastereo- and enantioselective cascade reaction between 3 isothiocyanato oxindoles and unsaturated isoxazolones.

Very recently Pedro, Blay and co-workers reported a conceptually similar process in which enantioenriched spirocyclic compounds bearing three contiguous stereocenters were obtained from 4-arylideneisoxazol-5-ones 123 and isocyanoacetate esters $\mathbf{1 2 4}$ through a formal $(3+2)$ cycloaddition reaction. ${ }^{63}$ Interestingly, high enantioselectivity and only two diastereomers were obtained by means of cooperative catalysis combining a classical bifunctional organocatalyst derived from a Cinchona alkaloid and silver oxide as Lewis acid (Scheme 25).

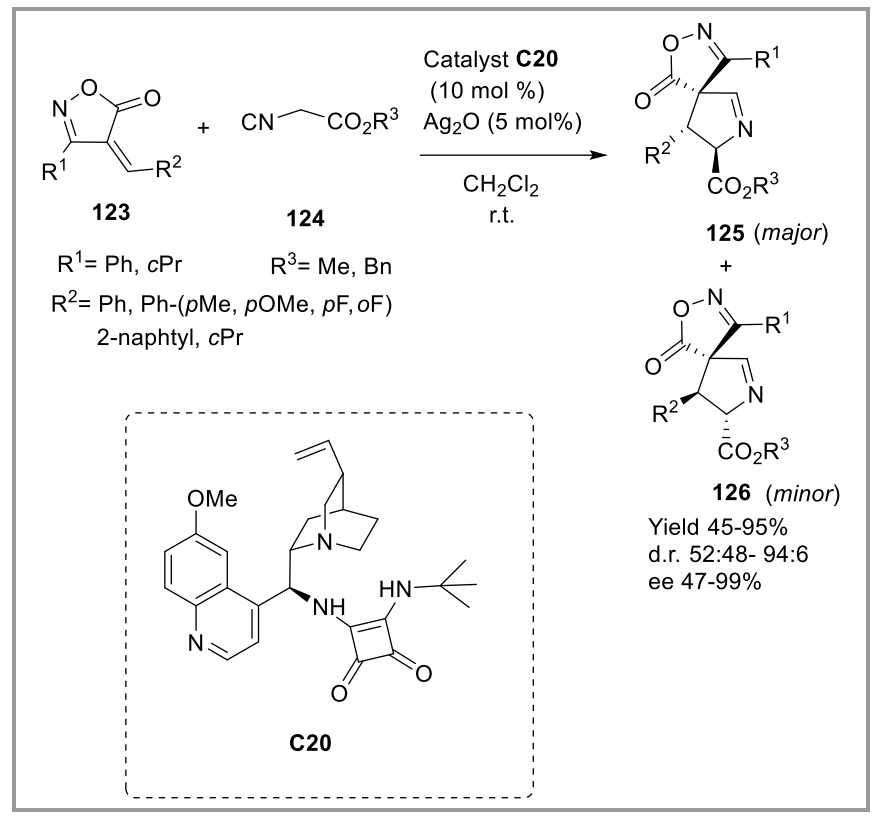

Scheme 25. Enantioselective synthesis of spirocyclic compounds through a formal $(3+2)$ cycloaddition reaction.

In 2017, Jurberg and co-workers ${ }^{61}$ have developed an asymmetric Michael reaction of arylideneisoxazol-5-ones $\mathbf{1 2 3}$ with acyclic and cyclic ketones $\mathbf{1 2 7}$ in the presence of cinchona-derived aminocatalysts $\mathbf{C 2 1}$ and substituted benzoic acids as co-catalysts (Scheme 26). The best results were obtained with modified catalysts bearing hindered substituents on the quinoline ring and mechanistic models have been proposed to explain the observed selectivity. Instead of their isolation, the Michael adducts 128 
were subjected to a controlled nitrosative degradation, according to Zard's conditions ${ }^{24,25}$ leading to alkyne motifs 129 bearing two contiguous stereocenters.

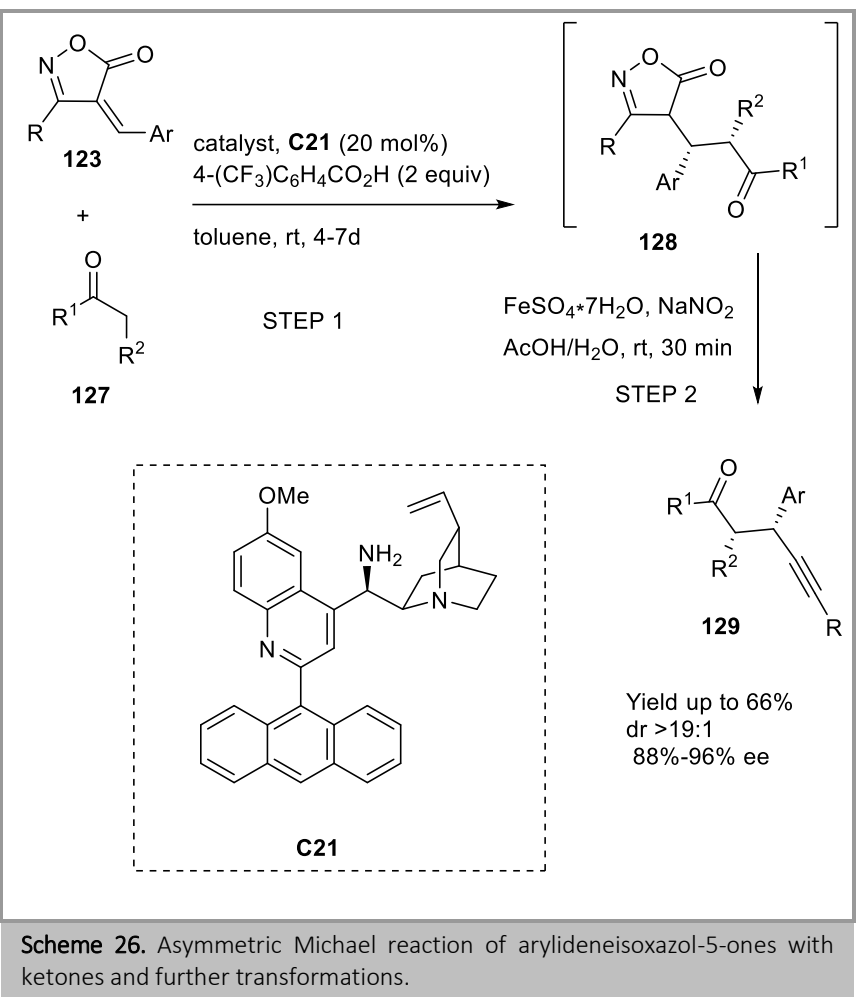

In 2018, the group of Chen and Ouyang64 reported a diastereodivergent asymmetric formal $(4+2)$ cycloaddition reaction, realized with Z-configured 4-alkylideneisoxazol-5-ones 123 and 2,4-dienone 130 in the presence of bifunctional chiral primary amine $\mathbf{C 2 2}$ as catalyst in combination with benzoic acid (Scheme 27-A). As a previous mechanistic study suggested, ${ }^{65}$ the $\gamma^{\prime}, \delta-(4+2)$ reaction might proceed via iminium ion catalysis in a stepwise cascade manner rather than a concerted Diels-Alder cycloaddition pathway. The authors also investigated a threecomponent reaction of 2,4-dienone 132, 3-methylisoxazol5(4H)-one 133, and benzaldehyde 53 (Scheme 27-B). ${ }^{64}$ This reaction was efficiently promoted under the catalysis of bifunctional C22 and the acid A2, through a cascade Knoevenagel condensation / formal (4+2) cycloaddition process. The addition of $4 \AA$ molecular sieves (MS) was beneficial for the enantioselectivity. These results also suggested the possibility to develop a more challenging and complicated four component cascade reaction process (Scheme 27-C), 64 involving condensations of simple 3-methyl-2cyclohexenone 135 and 3-methyl-isoxazol-5(4H)-one 133 with aldehydes 74, respectively, followed by the formal $(4+2)$ cycloaddition. In this case the bifunctional amine-thiourea C22 failed to deliver the desired product probably because it might not be effective for the formation of dienone 130. However, the authors discovered that adding $10 \mathrm{~mol} \%$ of cinchona-based amine $\mathbf{C 2 3}$, in combination with catalyst $\mathbf{C 2 4}$, could afford the cycloadducts ent-131 in moderate yields with high enantioselectivity, probably proceeding in a relay aminocatalytic manner.

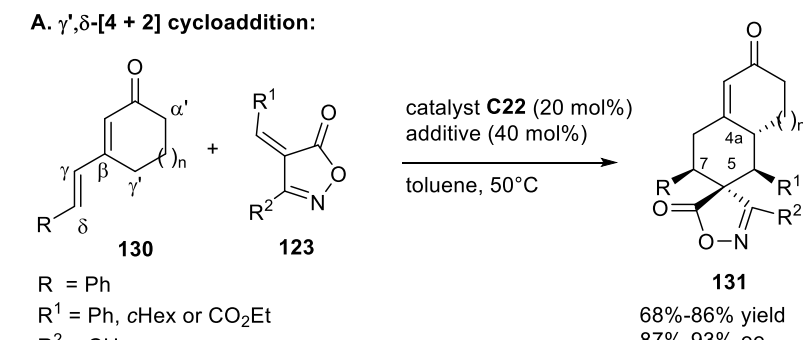

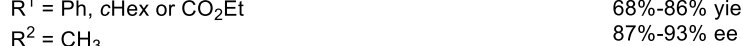

B. Three-component reaction:

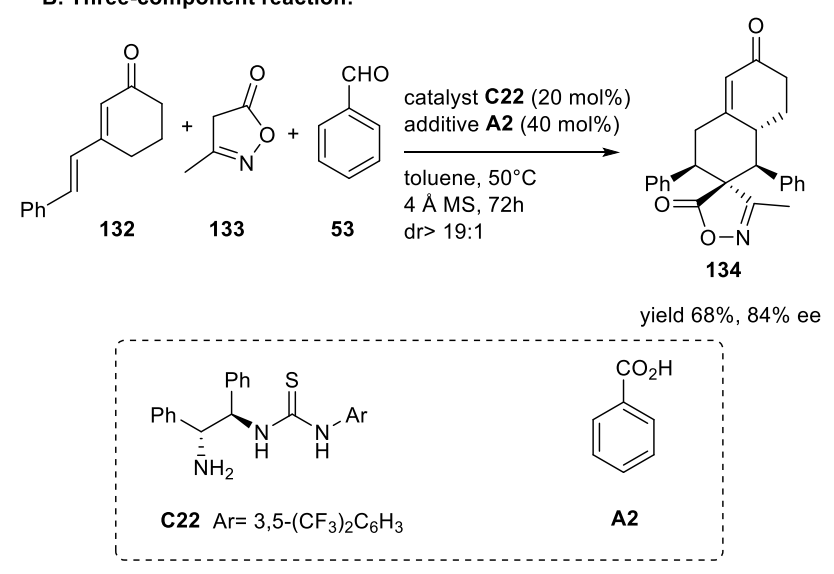

C. Four-component cascade reaction:
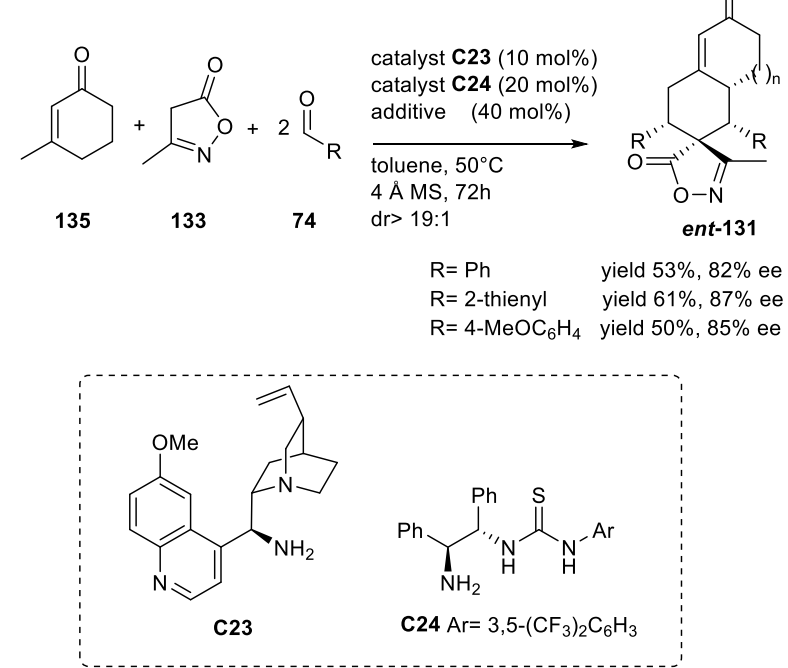

Scheme 27. Diastereodivergent, asymmetric formal $(4+2)$ cycloaddition reaction.

In 2019, Yu, Zhou et al.66 reported a domino oxa-Michael/1,6addition reaction of orthohydroxyphenylsubstituted p-QMs 137 and unsaturated isoxazolones 136 (Scheme 28). Various new spiroisoxazolonechromans 138 were obtained in good yields (up to $89 \%$ ) with excellent diastereoselectivities (>99:1 dr) in the presence of $\mathrm{Et}_{3} \mathrm{~N}$, while preliminary investigation of asymmetric versions in the presence of quinine allowed the obtaining of the target compound in high yield and moderate diastereo- and enantio-selectivity. 


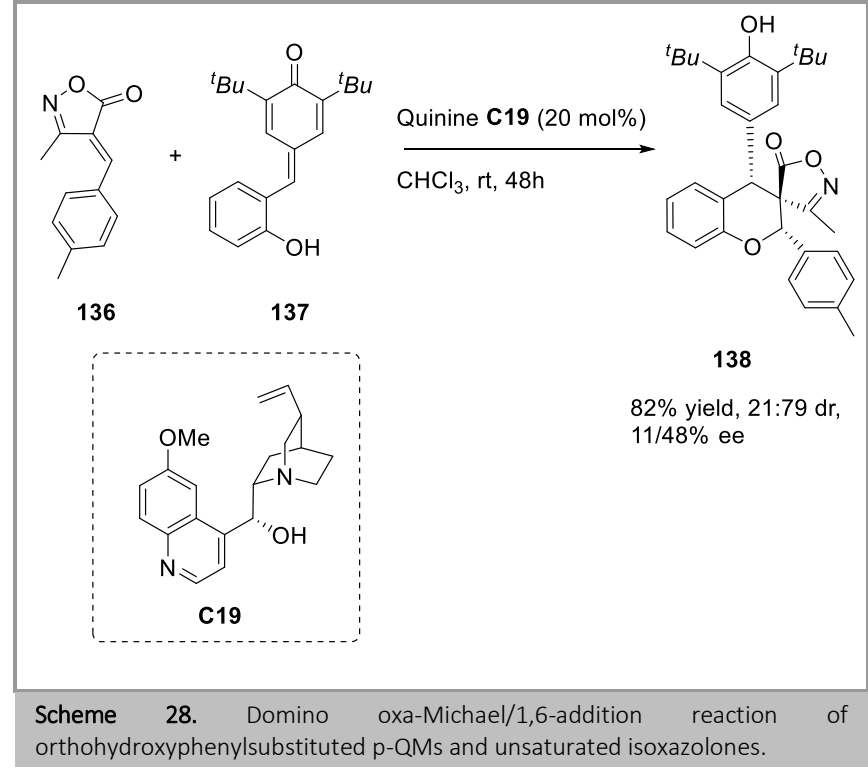

On the basis of previous works in which the strategy of the entrapping of unstable intermediates allowed the isolation and transformation of challenging aldol adducts $^{67}$ or useful heterocycles, ${ }^{68-70}$ very recently Massa et al. reported the first asymmetric Michael reaction of arylideneisoxazol-5-one $\mathbf{1 2 3}$ with 1,3-diesters 139 (Scheme 29). ${ }^{60}$ Despite complex tautomer equilibria of the obtained Michael adducts (Int-141-143), as demonstrated by ${ }^{1} \mathrm{H}-\mathrm{NMR}$ spectroscopy, the one-pot entrapping by the aid of different electrophiles/protecting groups ( $E X=(B o c)_{2} \mathrm{O}, \mathrm{Ac}_{2} \mathrm{O}$ or $\mathrm{CH}_{3} \mathrm{I}$ ) led to the regioselective isolation of diverse $N$-substituted isoxazol-5-ones 140 in very high overall yield and with good enantioselectivities up to $94 / 6$ er. The reaction can be performed in two ways: in a sequential fashion, carrying out the Michael addition first and then quenching with (Boc) ${ }_{2} \mathrm{O}$ or $\mathrm{Ac}_{2} \mathrm{O}$ (Scheme 29-A), or in a truly one-pot procedure leading to comparable results in terms of yield and er (Scheme 29-B). Notably, the enantiopurity of several final products was further increased up to $>99.9 / 0.1$ er after a single crystallization in good overall yield. The use of quinidine $\mathbf{C 2 5}$ as a cheap and readily available catalyst also allowed the development of onepot four-component Knoevenagel / Michael / tautomer trapping (Scheme 29-C). Also, in this case the reaction was highly regioselective and, despite the lower yield 146 (80\%) and the only moderate er $(77 / 23)$, this procedure has the advantage to overcome the synthesis of the arylideneisoxazol-5-one 144.

\section{A. Sequential one-pot Michael / tautomer entrapping}

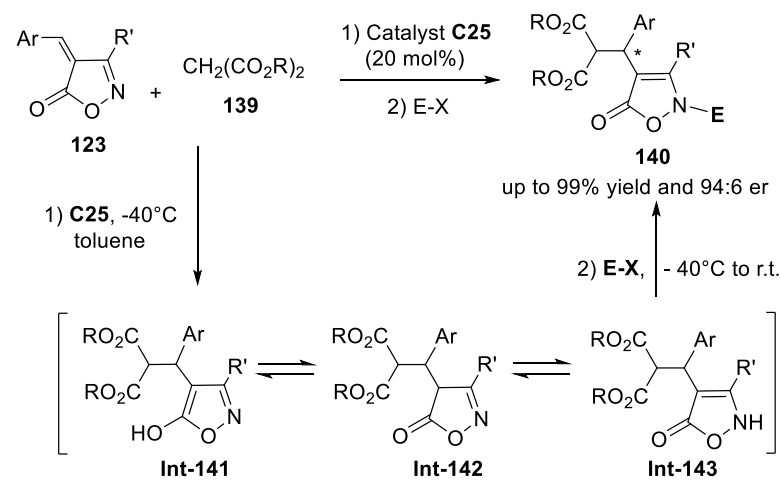

$\mathrm{R}^{\prime}=\mathrm{Me}, \mathrm{Ph},{ }^{i} \mathrm{Pr}$ or ${ }^{n} \mathrm{Pr}$

$\mathrm{Ar}=\mathrm{Ph}, \mathrm{Ph}\left(2-\mathrm{Cl}, 3-\mathrm{NO}_{2}, 4-\mathrm{OMe}\right), 1$-naphtyl or 2-naphtyl $\mathrm{OMe}$ $\mathrm{R}=\mathrm{CH}_{3}, \mathrm{CH}_{2} \mathrm{CH}_{3},\left(\mathrm{CH}_{3}\right)_{2} \mathrm{CH}$ or $\mathrm{CH}_{3}-\mathrm{Ph}$ $\mathrm{E}-\mathrm{X}=(\mathrm{Boc})_{2} \mathrm{O}, \mathrm{Ac}_{2} \mathrm{O}, \mathrm{CH}_{3} \mathrm{I}$
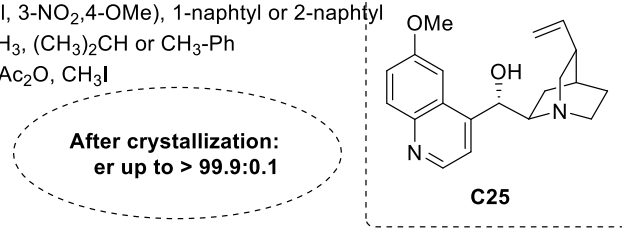

B. Three-component one-pot Michael / tautomer entrapping:

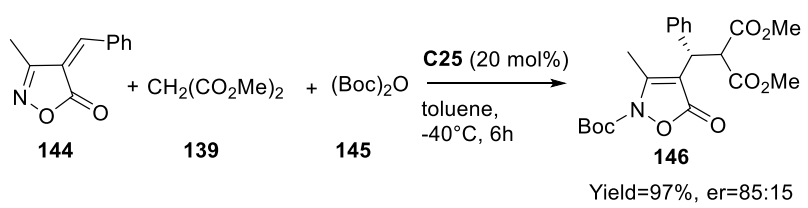

C. Four-component one-pot Knovenagel / Michael / tautomer entrapping:

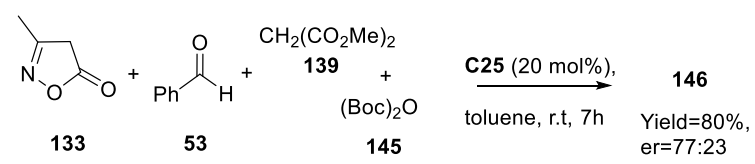

Scheme 29. Asymmetric one-pot Michael reactions/tautomer trapping of arylideneisoxazol-5 ones.

\section{Conclusions}

In this review we have presented the most common strategies for the asymmetric construction of isoxazol-5-one and isoxazolidin-5-one heterocyclic compounds. On the basis of the examples herein analyzed, several similarities but also some differences are shown between these two groups of heterocycles. These features not only affect the asymmetric synthesis strategies but also their further transformations to access other useful building blocks or different heterocycles. Even though both chiral metal catalysts and organocatalysts have been successfully used in the last years, it clearly appears that this is a research field still under-explored and it is easy to predict that the closer future will bring other asymmetric strategies and new transformations which will enlarge the chemical diversity and the applications of these fascinating organic molecules.

\section{Funding Information}

AM wants to thank the Ministero dell'Università e della Ricerca (MIUR) and Università degli Studi di Salerno for financial 
support. AE and MW gratefully acknowledge financial support from the Austrian Science Funds (FWF): Project No. P30237. JFB acknowledge that this work has been partially supported by INSA Rouen Normandy, University of Rouen Normandy, the Centre National de la Recherche Scientifique (CNRS), EFRD, and Labex SynOrg (ANR-11-LABX-0029), and by Region Normandie (CRUNCh network).

\section{Biosketches}

Antonio Macchia was born in Potenza, Italy in 1992. He started
studying chemistry at the University of Basilicata in 2011 and
graduated in 2017 in the Dr. Paolo Lupattelli group. His Master's
thesis focussed on the total synthesis of Myricanol. He moved at
University of Salerno in the Prof. Massa group for PhD studies on
enantioselective syntheses of isoxazol-5-ones and isoindolinones.

\begin{tabular}{|l|l|}
\hline & $\begin{array}{l}\text { Andreas Eitzinger was born in Linz, Austria in 1993. He started } \\
\text { studying chemistry at the Johannes Kepler University Linz in } 2011 \text { and } \\
\text { graduated in } 2017 \text { in the Mario Waser group. His Master's thesis } \\
\text { focussed on phosphine-catalysed annulation reactions of allenoates } \\
\text { and azlactones. He stayed in the group and has since been carrying out } \\
\text { PhD studies on enantioselective syntheses of fluorinated amino acids. }\end{array}$ \\
\hline
\end{tabular}

\begin{tabular}{|l|l|}
\hline Dr Jean-François Brière (born in France in 1971) completed his PhD with Prof Guy Quéguiner \\
(1998, France - heterocycles synthesis) and was a postdoctoral fellow with Prof Henk Hiemstra \\
$(1999-2001$, the Netherlands - total synthesis) and Prof Istvan E. Markó (2001-02, Belgium, NHC \\
in metallocatalysis) in collaboration with Rhodia Company. Recruited in 2002 (Caen Normandy \\
University, France - Sulfur chemistry), Brière is currently CNRS senior research scientist in the \\
Heterocycles team at laboratory COBRA (since 2007, Rouen Normandy University, France) and \\
develops (organo)catalytic processes for the construction of bio-relevant chiral heterocycles.
\end{tabular}

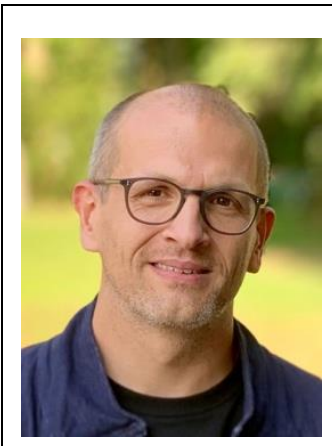

Mario Waser was born in Steyr, Austria in 1977 and studied chemistry at JKU Linz, Austria where he obtained his Ph.D. in 2005 in the group of Prof. Heinz Falk. After a postdoctoral stay with Prof. Alois Fürstner (Max-Planck Institut für Kohlenforschung, Mülheim, Germany), he spent two years as an R\&D chemist working for DSM. In 2009 he started his independent career at JKU Linz. In 2014 he obtained his habilitation (venia docendi) and became Associate Professor and in 2020 he became Full Professor for Organic Stereochemistry. His main research interests are on the design and application of asymmetric organocatalysts (i.e. ion pairing catalysts) and on the development of asymmetric organocatalytic synthesis methods. 


\begin{tabular}{|l|l|}
\hline & $\begin{array}{l}\text { Antonio Massa was born in Cava dei Tirreni, Italy in 1971. After obtaining his Ms degree in chemistry at } \\
\text { University of Salerno (Italy) in 1996, he worked for three years in R\&D in the company Montefibre. In } \\
2003 \text { he obtained his PhD in organic chemistry in Salerno (supervisor prof. A. Scettri). After post-doc, in } \\
2004 \text { he became assistant professor at University of Salerno. In } 2002 \text { he was visiting investigator at } \\
\text { University of Glasgow (UK) in prof. Kočovsky's lab and in } 2008 \text { at the SCRIPPS in San Diego (USA) with a } \\
\text { Fulbright scholarship in prof. Barbas III's lab. Since } 2015 \text { he is currently associate professor and in } 2017 \\
\text { he obtained his habilitation as full professor. His main research interests are on the development of new } \\
\text { synthetic methodologies and scale-up, in asymmetric catalysis and on the synthesis of bioactive } \\
\text { compounds. He is involved in several collaborations and is consultant of pharma companies. }\end{array}$ \\
\hline
\end{tabular}

\section{References:}

${ }^{1}$ Lambein, F.; Kuo, Y.-H.; Van Parijs, R. Heterocycles 1976, 4, 567.

2 Rozan, P.; Kuo, Y.-H.; Lambein, F. Phytochemistry 2001, 58, 281.

3 a) Kuo, Y.-H.; Ikegami, F.; Lambein, F. Phytochemistry 1998, 38, 32.; b) Rozan, P.; Kuo, Y. H.; Lambein, F. Amino Acids $2001,20,319$.

${ }^{4}$ (a) Iwama, T.; Nagai, Y.; Tamura, N.; Harada, S.; Nagaoka, A. Eur.J. Pharmacol. 1991, 197, 187. See also: (b) Yu, M.; Wang, J.; Tang, K.; Shi, X.; Wang, S.; Zhu, W.-M.; Zhang, X.-H. Microbiology 2012, 158, 835. (c) Becker, T.; Pasteels, J.; Weigel, C.; Dahse, H.- M.; Voigt, K.; Boland, W. Nat. Prod. Rep. 2017, 34, 343.

${ }^{5}$ Hedner, E.; Sjögren, M.; Hodzic, S.; Andersson, R.; Göransson, U.; Jonsson, P. R.; Bohlin, L. J. Nat. Prod. $2008,71,330$.

${ }^{6}$ a) Sugeno, W.; Matsuda, K. Appl. Entomol. Zool. 2002, 37, 191. b) Becker, T.; Ploss, K.; Boland, W. Org. Biomol. Chem. 2016, $14,6274$.

${ }^{7}$ (a) Kafle, B.; Aher, N. G.; Khadka, D.; Park, H.; Cho, H. Chem. Asian J. 2011, 6, 2073. See also, for antidiabetic agents: (b) Kees, K. L.; Caggiano, T. J.; Steiner, K. E.; Fitzgerald, J. J. Jr.; Kates, M. J.; Christos, T. E.; Kulishoff, J. M. Jr.; Moore, R. D.; McCaleb, M. L. J. Med. Chem. $1995,38,617$.

${ }^{8}$ (a) Mahajan, S. S.; Scian, M.; Sripathy, S.; Posakony, J.; Lao, U.; Loe, T. K.; Leko, V.; Thalhofer, A.; Schuler, A. D.; Bedalov, A.; Simon, J. A. J. Med. Chem. 2014, 57, 3283. (b) Tong, Y.; Stewart, K. D.; Thomas, S.; Przytulinska, M.; Johnson, E. F.; Klinghofer, V.; Leverson, J.; McCall, O.; Soni, N. B.; Luo, Y.; Lin, N.-H.; Sowin, T. J.; Giranda, V. L.; Penning, T. D. Bioorg. Med. Chem. Lett. 2008, 18,5, 206.

${ }^{9}$ Hung, T. V.; Janowski, W. K.; Prager, R. H. Aust. J. Chem. 1985, 38,931.

10 a) Vergelli, F.; Schepetkin, C. I. A.; Crocetti, L.; Iacovone, A.; Giovannoni, M. P.; Guerrini, G.; Khlebnikov, A. I.; Ciattini, S.; Ciciani, G.; Quinn, M. T. J. Enz. Inhib. Med. Chem. 2017, 32, 821. b) Giovannoni, M. P.; Crocetti, L.; Cantini, N.; Guerrini, G.; Vergelli, C.; Iacovone, A.; Teodori, E.; Schepetkin, I. A.; Quinn, M. T.; Ciattini, S.; Rossi, P.; Paoli P. Drug Dev Res. 2020, 81, 338.

${ }^{11}$ Snyder, L. B.; Meng, Z.; Mate, R.; Andrea, S. V. D.; Marinier, A.; Quesnelle, C. A.; Gill, P.; DenBleyker, K. L.; Fung-Tomc, J. C.; Frosco, M. B.; Martel, A.; Barretta, J. F.; Bronson, J. J. Bioorg. Med. Chem. Lett. 2004, 14, 4735.

12 Laufer, S. A.; Margutti, S. J. Med. Chem. 2008, 51, 2580.

${ }^{13}$ Laurent, P.; Braekman, J.-C.; Daloze, D. Top. Curr. Chem. 2005, 240, 167.

14 a) Kiyani, H.; Ghorbani, F. Heterocycl. Lett. 2013, 3, 145.; b) Conti, P.; Tamborini, L.; Pinto, A.; Sola, L.; Ettari, R.; Mercurio, C.; Micheli, C. D. Eur. J. Med. Chem. 2010, 45, 4331.; c) Deng, B.-L.; Cullen, M. D.; Zhou, Z.; Hartman, T. L.; Buckheit Jr., R. W.; Pannecouque, C.; Clercq, E. D.; Fanwick, P. E.; Cushman, M. Bioorg. Med. Chem. 2006, 14, 2366.

15 Ferrazzano, L.; Viola, A.; Lonati, E.; Bulbarelli, A.; Musumeci, R.; Cocuzza, C.; Lombardo, M.; Tolomelli, A., Eur. J. of Med. Chem.2016, $124,906$.

${ }^{16}$ Karabasanagouda,T.; Adhikari, T. A. V.; Girisha, M. Indian J. Chem. 2009, 48,430.

17 Mueller, Thomas et al. PCT Int. Appl. (2018), WO 2018178008 A1 Oct 04, 2018.

${ }^{18}$ Basak, P.; Dey, S.; and Ghosh, P. ChemistrySelect 2020, 5, 626.

${ }^{19}$ Becker, T.; Görls, H.; Pauls, G.; Wedekind, R.; Kai, M.; Boland, W. J. Org. Chem. 2013, 78, 12779.

${ }^{20}$ Feng, G.; Satoshi, I.; Takuya, Y.; Akira, U.; Yukari, S.; Hiroshi, M. Plant Science 2019,283, 321.

${ }^{21}$ (a) Lehtonen, K.; Summers, L. A.; Carter, G. A. Pestic. Sci. 1972, 3, 357. (b) Kömürcü, Ş. G.; Rollas, S.; Yilmaz, N.; Çevikbaş, A. Drug Metabol. Drug Interact. 1995, 12, 161.

${ }^{22}$ Hong, S.; Wei-Bing, F.; Feng, C.; De-Qing, S. J. Heterocyclic. Chem. 2013, 50(6), 1381.

${ }^{23}$ a) Da Silva, F.; Fernandes, A. A. G.; Thurow, S.; Stivanin, M. L.; Jurberg I. D. Synthesis 2018, 50, 2473. b) Fernandes, A. A. G.; da Silva, A. F.; Thurow, S.; Okada Jr., C. Y.; Jurber I. D. Targets in Heterocyclic Systems, 2018, 409. Eds Attanazi, O. A.; Merino, P.; Spinelli, D.; Italian Society of Chemistry (Book Chapter).

${ }^{24}$ Review: Zard, S. Z. Chem. Commun. 2002, 1555.

25 (a) Abidi, S. L. J. Chem. Soc., Chem.Commun. 1985, 1222. (b) Abidi, S. L. Tetrahedron Lett. 1986, 27,

267. (c) Abidi, S. L. J. Org. Chem. 1986, 51, 2687. (d) Corey, E. J.; Seibel, W. L.; Kappos, J. C. Tetrahedron Lett. 1987, 28, 4921. (e) Boivin, J.; Elkaim, L.; Ferro, P. G.; Zard, S. Z. Tetrahedron Lett. 1991, 32, 5321.

${ }^{26}$ Annibaletto, J.; Oudeyer, S.; Levacher, V.; Brière, J.-F. Synthesis 2017, 49, 2117.

27 Benson, S. W. J. Chem. Educ. 1965, 42, 502.

${ }^{28}$ (a) Baldwin, J. E.; Harwood, L. M.; Lombard, M. J. Tetrahedron 1984, 40, 4363. (b) Baldwin, J. E.; Adlington, R. M.; Mellor, L. C. Tetrahedron 1994, 50, 5049. (c) Pearson, C.; Rinehart, K. L.; Sugano, M.; Costerison, J. R. Org. Lett. 2000, 2, 2901. (d) Lee, H.-S.; Park, J.-S.; Kim, B. M.; Gellman, S. H. J. Org. Chem. 2003, 68, 1575 .

${ }_{29}$ Rieckhoff, S.; Meisner, J.; Katner, J.; Frey, W.; Peters, R. Angew. Chem. Int. Ed. 2018, 57, 1404.

${ }^{30}$ Meng, W.; Zheng, Y.; Nie J.; Xiong, H.; Ma, J. J. Org. Chem. 2013, 78, 559.

31 Zhang, H.; Wang, B.; Cui, L.; Bao, X.; Qu, J.; Song, Y. Eur. J. Org. Chem. 2015, 2143. 
${ }^{32}$ Hellmuth, T.; Frey, W.; Peters, R. Angew. Chem. Int. Ed. 2015, 54(9), 2788.

33 Torán, R.; Vila, C.; Sanz-Marco, A.; Muñoz, M.C.; Pedro, J. R.; Blay, G. Eur.J.Org. Chem, 2020,5, 627.

${ }^{34}$ Qi, S.; Jiang, Z; Chu, M.; Wang, Y.; Chen, X.; Ju, W.; Xu, D. Org. Biomol. Chem 2020, 18(13), 2398.

35 Xiao, W.; Zhou, Z.; Yang, Q.; Du, W.; Chen, Y. Adv. Synth. Catal. 2018, 360(18), 3526.

36 Li, L.; Luo, P.; Deng, Y.; Shao, Z. Angew. Chem. Int. Ed. 2019, 58(14), 4710.

37 (a) Baldwin, S. W.; Aubé, J. Tetrahedron Lett. 1987, 28, 179. (b) Ishikawa, T.; Nagai, K.; Kudoh, T.; Saito, S. Synlett 1995, 1171. (c) Niu, D.; Zhao, K. J. Am. Chem. Soc. 1999, 121, 2456.

38 (a) Sibi, M. P.; Liu, M. Org. Lett. 2000, 2, 3393. (b) Sibi, M. P.; Prabagaran, N.; Ghorpade, S. G.; Jasperse, C. P. J. Am. Chem. Soc. 2003 , $125,11796$.

${ }^{39}$ Izumi, S.; Kobayashi, Y.; Takemoto, Y. Org. Lett. 2016, 18, 696.

${ }^{40}$ Berini, C.; Sebban, M.; Oulyadi, H.; Sanselme, M.; Levacher, V.; Brière, J.-F. Org. Lett. 2015, $17,5408$.

41 (a) Ibrahem, I.; Rios, R.; Vesely, J.; Zhao, G.-L.; Córdova, A. Chem. Commun. 2007, 849. (b) Pou, A.; Moyano, A. Eur. J. Org. Chem. 2013, 3103. (c) Jiang, H.-T.; Gao, H.-L.; Ge, C.-S. Chin. Chem. Lett. 2017, 28, 471. (d) Lai, J.; Sayalero, S.; Ferrali, A.; Osorio-Planes, L.; Bravo, F.; Rodriguez-Escrich, C.; Pericas, M. A. Adv. Synth. Catal. 2018, 360, 2914. (e) Gao, H.; Yu, J.; Ge, C.; Jiang, Q. Molecules 2018, $23,1440$.

42 (a) Zhang, H.; Zhang, S.-J.; Zhou, Q.; Dong, L.; Chen, Y.-C. Beilstein J. Org. Chem. 2012, 8, 1241.

${ }^{43}$ Kamlar, M.; Cisarova, I.; Hybelbauerova, S.; Vesely, J. Eur. J. Org. Chem. 2017, 1926.

${ }^{44}$ Martzel, T.; Annibaletto, J.; Millet, P.; Pair, E.; Sanselme, M.; Oudeyer, S.; Levacher, V.; Brière, J.-F. Chem. Eur. J. 2020, $10.1002 /$ chem.202001214.

${ }^{45}$ Pair, E.; Cadart, T.; Levacher, V.; Brière, J.-F. ChemCatChem 2016, 8, 1882.

${ }^{46}$ (a) Seayad, J.; Patra, P. K.; Zhang, Y.; Ying, J. Y. Org. Lett. 2008, 10, 953. (b) Nawaz, F.; Zaghouani, M.; Bonne, D.; Chuzel, O.; Rodriguez, J.; Coquerel, Y. Eur. J. Org. Chem. 2013, 8253.

${ }^{47}$ Ji, S.-P.; Liu, L.-W.; Chen, F.; Ren, H.-X.; Yang, Y.; Zhang, Z.-B.; Peng, L.; Wang, L.-X. Eur. J. Org. Chem. 2016, 5437.

48 (a) Shindo, M.; Itoh, K.; Ohtsuki, K.; Tsuchiya, C.; Shishido, K. Synthesis 2003, 1441. (b) Luisi, R.; Capriati, V.; Florio, S.; Vista, T. J. Org. Chem. 2013, 68, 9861.

${ }^{49}$ (a) Postikova, S.; Tite, T.; Levacher, V.; Brière, J.-F. Adv. Synth. Catal. 2013, 355, 2513. (b) Tite, T.; Sabbah, M.; Levacher, V.; Brière, J.-F. Chem. Commun. 2013, 49, 11569.

${ }^{50}$ Cadart, T.; Berthonneau, C.; Levacher, V.; Perrio, S.; Brière, J.-F. Chem. Eur. J. 2016, 43, 15261.

51 (a) Cadart, T.; Levacher, V.; Perrio, S.; Brière, J.-F. Adv. Synth. Catal., 2018, 360, 1499; (b) Capaccio, V.; Zielke, K.; Eitzinger, A.; Massa, A.; Palombi, L.; Faust, K.; Waser, M. Org. Chem. Front., 2018, 5, 3336; (c) Eitzinger, A.; Winter, M.; Schörgenhumer, J.; Waser, M. Chem. Commun., 2020, 56, 579 .

52 (a) Capaccio, V.; Sicignano, M.; Rodriguez, R. I.; Della Sala, G.; Aleman, J. Org. Lett., 2020, 22, 219. (b) Eitzinger, A.; Brière, J.-F.; Cahard, D.; Waser, M. Org. Biomol. Chem. 2020, 18, 405.

${ }^{53}$ (a) Yu, J.-S.; Noda, H.; Shibasaki, M. Angew. Chem., Int. Ed., 2018, 57, 818; (b) De Oliveira, M. N.; Arseniyadis, S.; Cossy, J. Chem. Eur. J., 2018, 24, 4810.

54 (a) Yu, J.-S.; Noda, H.; Shibasaki, M. Chem. Eur. J., 2018, 24, 15796. (b) Amemiya, F.; Noda, H.; Shibasaki, M. Chem. Pharm. Bull., 2019, 67, 1046.

55 (a) Yu, J.-S.; Espinosa, M.; Noda, H.; Shibasaki, M., J. Am. Chem. Soc. 2019, 141, 10530. (b) Espinosa, M.; Noda, H.; Shibasaki, M. Org. Lett. 2019, $21,9296$.

${ }^{56}$ Seminal report about the use of such catalysts: Ooi, T.; Kameda, M.; Maruoka, K. J. Am. Chem. Soc. 1999, 121, 6519.

57 For some illustrative overviews: (a) Shirakawa, S.; Maruoka, K. Angew. Chem., Int. Ed., 2013, 52, 4312. (b) Qia, D.; Sun, J., Chem. Eur. J. 2019, 25, 3740. (c) Nakamura; T.; Okuno, K.; Nishiyori, R.; Shirakawa, S. Chem. Asian J. 2020, 15, 463.

${ }^{58}$ (a) Bode, J. W.M.; Fox, R. M.; Baucom, K. D. Angew. Chem. Int. Ed. 2006, 45, 1248. (b) Wucherpfennig, T. G.; Pattabiraman, V. R.; Limberg, F. R. P.; Ruiz-Rodriguez, J.; Bode, J. W. Angew. Chem. Int. Ed. 2014, 53, 12248.

${ }^{59}$ Cui B., Li S., Zuo J., Wu Z., Zhang X., Yuan W. Tetrahedron 2014, 70, 1895.

${ }^{60}$ Macchia, A.; Cuomo, V. D.; Di Mola, A.; Pierri, G.; Tedesco, C.; Palombi, L.; Massa, A., Eur. J. Org. Chem., 2020, $15,2264$.

${ }^{61}$ Jurberg, I.D. Chem. Eur. J. 2017, 23, 9716.

62 Parveen, M.; Aslam A.; Ahmad A.; Alam M.; Silva M. R.; Silva P.S. P. J. Mol. Struct. 2020, 1200, 127067.

${ }^{63}$ Martínez-Pardo, P.; Laviós, A.; Sanz-Marco, A.; Vila, C.; Pedro, J. R.; Blay, G. Adv. Synth. Catal., 2020, doi10.1002/adsc.202000611.

${ }^{64}$ Xiao, W.; Yang, Q.; Chen, Z.; Ouyang, Q.; Du, W.; Chen, Y. Org. Lett. 2018, 20, 236

${ }^{65}$ Feng, X.; Zhou, Z.; Zhou, R.; Zhou, Q.-Q.; Dong, L.; Chen, Y.-C. J. Am. Chem. Soc. 2012, 134, 19942

${ }^{66}$ Ye, Z.; Bai, L.; Bai, Y.; Gan, Z.; Zhou, H.; Pan, T.; Yu, Y.; Zhou, J. Tetrahedron 2019, 75, 682.

${ }^{67}$ Massa, A.; Roscigno, A.; De Caprariis, P.; Filosa, R.; Di Mola, A. Adv. Synth. Catal., 2010, 352, 3348.

${ }^{68}$ More, V.; Di Mola, A.; Perillo, M.; De Caprariis, P.; Filosa, R.; Peduto, A.; Massa A. Synthesis, 2011, $18,3027$.

${ }^{69}$ Di Mola A.; Di Martino M.; Capaccio V.; Pierri G.; Palombi L.; Tedesco C.; Massa A. Eur. J. Org. Chem., 2018, 1699

${ }^{70}$ Di Mola A.; Macchia A.; Tedesco C.; Pierri G.; Palombi L.; Filosa R.; Massa A. ChemistrySelect, 2019, 4, 4820 